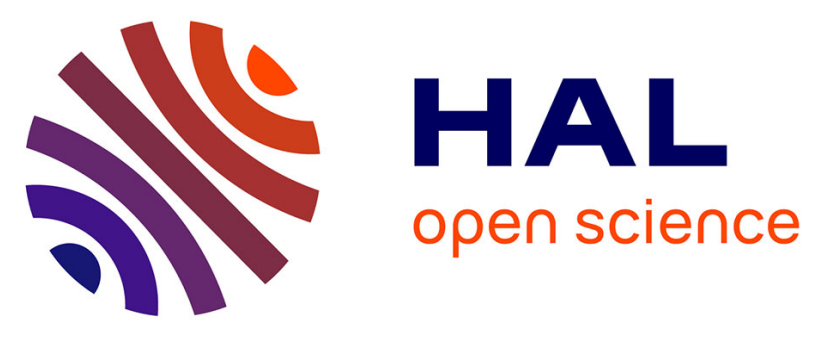

\title{
Modal abundance, density and chemistry of micrometer-sized assemblages by advanced electron microscopy: Application to chondrites
}

Pierre Marie Zanetta, Corentin Le Guillou, Hugues Leroux, B. Zanda, R.H. Hewins, E. Lewin, S. Pont

\section{To cite this version:}

Pierre Marie Zanetta, Corentin Le Guillou, Hugues Leroux, B. Zanda, R.H. Hewins, et al.. Modal abundance, density and chemistry of micrometer-sized assemblages by advanced electron microscopy: Application to chondrites. Chemical Geology, 2019, Chemical Geology, 514, pp.27-41. 10.1016/j.chemgeo.2019.03.025 . hal-02090098

\section{HAL Id: hal-02090098 \\ https://hal.univ-lille.fr/hal-02090098}

Submitted on 22 Oct 2021

HAL is a multi-disciplinary open access archive for the deposit and dissemination of scientific research documents, whether they are published or not. The documents may come from teaching and research institutions in France or abroad, or from public or private research centers.
L'archive ouverte pluridisciplinaire HAL, est destinée au dépôt et à la diffusion de documents scientifiques de niveau recherche, publiés ou non, émanant des établissements d'enseignement et de recherche français ou étrangers, des laboratoires publics ou privés.

\section{(ㄷ)(1) $\$$}

Distributed under a Creative Commons Attribution - NonCommerciall 4.0 International 


\title{
Modal abundance, density and chemistry of micrometer-sized assemblages by advanced electron microscopy: application to chondrites
}

\author{
P-M. Zanetta 1,2 , C. Le Guillou, , H. Leroux 1 , B. Zanda ${ }_{2,3,4}$, R.H. Hewins, 2,3 , E. Lewin 5 and S. Pont 2. \\ 1. Univ. Lille, CNRS, INRA, ENSCL, UMR 8207 - UMET - Unité Matériaux et Transformations, F-59000 \\ Lille, France ; 2. IMPMC, Sorbonne Université, MNHN, UPMC Paris 06, UMR CNRS 7590, 75005 Paris, \\ France ; 3. EPS, Rutgers Univ., Piscataway, NJ 08854, USA ; 4. Observatoire de Paris, IMCCE, 75014 Paris, \\ France ; 5. ISTerre (OSUG : Univ. Grenoble Alpes \& INSU-CNRS), Grenoble, France. \\ (Pierre.marie.zanetta@gmail.com)
}

Keywords: Hyperspy; X-ray phase-mapping; Density map; Micro-assemblage compositions; Chondrite matrices;

\begin{abstract}
Numerous geosciences samples display a multi-scale mineralogical heterogeneity for which it is challenging to obtain spatially resolved quantitative chemical data. It is the case for chondritic meteorites, which can contain up to 10 different phases with grain size ranging from the nanometer to the millimeter. We developed a method providing multiple physical and chemical information by advanced scanning electron microscopy (SEM), hyperspectral energy dispersive X-ray spectroscopy (EDX) and electron probe micro-analyses (EPMA). The method includes: i) infra-micrometric low-voltage EDX mapping and innovative postacquisition hyperspectral data analysis (based on both clustering and multiple linear least square fitting) which allow phase mapping and quantification of the modal abundances; ii) EPMA of chemical end-members to upgrade the phase map into a quantified chemical map; iii) physical modelling of the EDX background, used as a proxy of the density. Density maps can be obtained with a precision of $\sim 10 \%$; iv) determination of the bulk sample composition by combining modal abundances, chemical analysis and density measurements.

The approach is applied to three well-known chondrites (Murchison, Paris and Orgueil), showing heterogeneous grain sizes and mineralogy. Areas of $\sim 250 * 250 \mu \mathrm{m}^{2}$ were mapped with a pixel size of $250 \mathrm{~nm}$ to determine the modal abundances, size distribution, circularity and densities of all phases, as well as the matrix bulk compositions. Taking bulk wet chemistry data as reference, ACADEMY leads to a better match than published defocused beam EPMA measurements. We demonstrate that choosing a Fe-rich, hydrated standard (a biotite) to quantify phyllosilicate by EPMA improves the quantification by up to $10 \%$, and we ultimately retrieve the $\mathrm{Mg} / \mathrm{Si}$ ratio with a $1 \%$ precision. We called this method ACADEMY for Analyzing the Composition, the modal Abundance and the Density using Electron MicroscopY. A code was developed and was made available online so that ACADEMY can be applied to other materials.
\end{abstract}

\section{Introduction}

The petrological and chemical description of natural samples is fundamental in Earth and Planetary Science. It permits us to constrain transformation processes which have shaped the matter and to reconstruct scenarios of rock formation. A number of these rocks consist of a fine-grained heterogeneous assemblage comprising various minerals (primary or secondary), cracks, porosity and filled veins. To analyze these samples properly, it is necessary to have at least access to the chemical bulk composition, the mineralogy (nature and 
composition of phases) and the petrofabrics (grain size, composition of phases, texture and structure). For this purpose, conventional tools such as scanning electron microscopy (SEM) and electron probe micro-analysis (EPMA) are used. These techniques offer a wide range of possibilities of routine studies, both for imaging, and chemical or structural analysis.

In their basic configuration, electron microscopy techniques have limits in terms of spatial resolution, especially in microanalysis. Difficulties arise when the scale of the study reaches the micrometer. SEM imaging is performed routinely with an accelerating voltage optimized for the targeted emission. A resolution of 1 to 10 nanometers is easily accessible by using secondary electron emission (SE). Backscattered electron (BSE) images, which give information on the average atomic number Z, display a lower resolution with a range between 100 and 500 nanometers (Brisset, Repoux, Grillon, \& Robaut, 2008) (Goldstein, et al., 2017). Lastly, when adapted for geological samples (taking into account the surface effects and the absorption characteristics), cathodoluminescence (CL) can be used with a maximum resolution of about 100-200 nanometers (Chen, Xu, \& Chen, 2015). Those imaging techniques are often combined with chemical characterization. Methods based on X-Ray emission such as energy dispersive X-ray spectroscopy (EDX) or wavelength dispersive X-ray spectroscopy (WDX) are used in a systematic way. However, working conditions of microanalysis are not well suited for fine-grained samples. Accelerating voltages of $15-20 \mathrm{kV}$ are usually used and lead to a spatial resolution of the order of a micrometer for the X-ray emission, which is much higher than that associated with the electronic imaging. A comparison of the volume probed is quite informative: for instance, for quartz (density $2.62 \mathrm{~g} / \mathrm{cm}^{3)}$ studied with an accelerating voltage of $15 \mathrm{keV}$, previous studies and Monte-Carlo simulations reveal that SE and BSE signals typically probe a volume of $\sim 1 \mathrm{E}-6 \mu \mathrm{m}^{3}$ and $\sim 0.125 \mu \mathrm{m}^{3}$ (Goldstein, et al., 2017) respectively while the volume probed by the X-Ray corresponds to $\sim 5 \mu \mathrm{m}^{3}$ (Drouin, et al., 2007). This spatial resolution limitation can be problematic for the $\varphi(\rho z)$ correction in case of strong density variation and beam overlapping of phases.

In addition to the spatial resolution limitation for microanalysis, fine-grained materials can introduce some difficulties related to the quantification procedure. Three major issues have been identified dealing with finegrained material:

- to obtain high resolved quantitative data over large area in a reasonable amount of time, the choice of the electron beam technique and its parametrization is a fundamental and a complex problematic. Both EDX and WDX provide chemical mappings over large areas with high number of pixels and they can be used in low -voltage condition to gain in spatial resolution. But those techniques have specificities that can put some restraints on their utilization. On the one hand EDX is fast and enables the measurement of all elements simultaneously. However, routine EDX is less adapted to a quantitative approach due to the peak overlap and a relatively low signal to noise ratio. On the other hand, WDX provides more accurate chemical composition (no peak overlap and better $\mathrm{S} / \mathrm{N}$ ratio) but requires a longer acquisition time.

- the quantitative mineralogy SEM-EDX and EPMA techniques provide X-ray data cubes and many software programs (PETROMAP®, XRMapAnal ${ }^{\circledR}, \quad$ QEMSCAN®, Zeiss ${ }^{\circledR}$, MAPS Mineralogy®, XMapTools®) or published thresholding methods (Tovey \& Krinsley, 1991); (Berrier, Hallaire, \& Curmi, 1999); (Pret, et al., 2010) allow us to construct phase maps and to retrieve the texture of grains. However, such data treatments remain generally applied to simple cases such as coarse-grained assemblages. In the case of fine-grained assemblages, the entanglement of the different minerals can lead to mixing zones under the beam and bias the modal abundances. Moreover, in natural samples, phases do not always display pure endmember compositions and the usual data treatments cannot be easily applied to solid solutions.

- An additional difficulty encountered with a heterogeneous fine-grained assemblage is the variability of density which can have a significant effect on the determination of the average sample composition. The different constituents of the material have their own chemistry and their own abundances in a given area but 
the combination of these two parameters is insufficient to obtain the bulk composition. Chemical analyses have to be weighted by the density of the different phases to correctly measure the composition of the sample (Ichinokawa, Kobayashi, \& Nakajima, 1969), (Warren, 1997), (Nazarov, Ignatenko, \& Shevaleevsky, 1982), (Zanda, Lewin, \& Humayun, 2018). In natural samples, a wide range of phase density can be encountered in a single sample, from $\sim 2 \mathrm{~g} / \mathrm{cm}^{3}$ for fibrous and highly porous material to $7-9 \mathrm{~g} / \mathrm{cm}^{3}$ for metallic phases. In meteorites, most phases have a known density (for forsterite, metal, sulfides for instance), but the density of very fine-grained regions, consisting of a mixture of amorphous phases, phyllosilicates, porosity, and nanophases can be difficult to estimate. Numerous methods exist to quantify the porosity (Hellmuth, SiitariKauppi, \& Lindberg, 1993) (Landry, 2005) (Oila, Sardini, Siitari-Kauppi, \& Hellmuth, 2005) (Anovitz \& Cole, 2015) (Liu, King, Huis, Drury, \& Plümper, 2016). Most of these methods have a spatial resolution not adapted to textural analyses of fine-grained rocks such as claystones, siltstones or primitive chondrites. They also require more powerful facilities than common electron microscopy or worse, might damage the sample. The porosity measurement method developed by (Pret, et al., 2010) based on the sum of oxide weight concentrations and measured using EPMA comes close to this resolution with a conventional tool. Even so, this method cannot be applied if organic matter or amorphous (non-stoichiometric) phases are part of the material constituents.

Here we propose a method named ACADEMY (Analyzing the Composition, the modal Abundance and the Density using Electron MicroscopY), which combines the advantages of two conventional and easily accessible techniques (SEM and EPMA) and the development of data treatment procedures, in order to improve the characterization of natural samples with fine-grained assemblages. This method aims to produce quantitative chemical maps with improved spatial resolution in combining the EDX spectrum, density and proxy EPMA analysis for each pixel. The method includes the following main steps:

- To decrease the volume of interaction and reach a higher spatial resolution, the hyperspectral maps are acquired with a lower accelerating voltage than conventional SEM-EDX working conditions.

- Complementary deconvolution procedures are added to the clustering method allowing us to obtain accurate modal abundances. These supplementary procedures deal with the problem of extreme mixing of micrometer-sized assemblages and the compositional variation existing in some mineral phases due to solid solutions.

- Quantitative chemical compositions of each phase are obtained by coupling SEM-EDX datasets with EMP point analyses (normal conditions $15 \mathrm{keV}$ ) allowing more accurate standard calibrations and correct $\varphi(\rho z)$ corrections.

- The density of the material is determined based on the modeling of the EDX background of the hyperspectral signal.

- The bulk chemical composition is retrieved through the combination of modal abundance and specific phase chemistry and density.

This thorough methodological development leads to a complete petrological description of the sample with an improved spatial resolution. This method is illustrated by examples of fine-grained matrices of primitive chondrites. Their investigation has been so far complicated by the extremely fine-grained nature, the mineralogical and compositional heterogeneity (including amorphous and partially altered phases), the wide range of density and the nano-porosity of the assemblage (Scott \& Krot, 2003). This method should yield more accurate description of those objects and better constrain processes which have shaped matter in the early Solar System. 


\section{Samples and analytical conditions}

\subsection{Samples}

The different steps of the ACADEMY method are described using fine-grained primitive chondrites as test samples. These meteorites consist of varied amounts of chondrules (droplets of igneous silicates), refractory inclusions (minerals condensed from the gas) and fine-grained interchondrule 'cement' named matrix. Although their formation mechanisms are not yet well established, chondrules and refractory inclusions have been extensively studied, e.g., (Hewins, 1997) (Russell, Connolly Jr, \& Krot, 2018) (Krot, et al., 2009). They are typically several hundred micrometers to millimeter objects, rendering their study relatively easy by various techniques (optical microscopy, SEM, EPMA, ion probe, ICPMS). The matrix is much more difficult to study because it consists of submicron grains entangled with each other, extremely heterogeneous in terms of compositions, structural states and densities. Matrices carry information on the origin and the evolution of the dust in the protoplanetary disk and have been mainly studied by transmission electron microscopy (TEM). (Brearley, 1993), (Greshake, 1997), (Chizmadia \& Brearley, 2008), (Le Guillou \& Brearley, 2014), (Leroux, Cuvillier, Zanda, \& Hewins, 2015) (Le Guillou, Changela, \& Brearley, 2015). Matrices consist of an unequilibrated mineral assemblage of a groundmass of amorphous silicates and phyllosilicates with numerous inclusions of anhydrous silicates, sulfides, metallic $\mathrm{Fe}, \mathrm{Ni}$, sulfates, carbonates and organic compounds. The size of the anhydrous silicates can vary from 0.1 to $10 \mu \mathrm{m}$. The groundmass of amorphous silicates is intermingled with phyllosilicates down to the nanometer scale. Moreover, phyllosilicates often crystallize in the form of intergrowths with a huge range of chemical variation between layers. These intergrowths are commonly serpentine interlayered with saponite, or tochilinite interlayered with cronstedtite (TCI), and exhibit numerous textures (Brearley, 2006). The matrix also contains significant inter-granular porosity (Leroux, Cuvillier, Zanda, \& Hewins, 2015). This heterogeneity is due to the strong mixture of components which originate directly from the protosolar dust and components formed by secondary processes on their parent body (Scott \& Krot, 2003).

We used two polished sections of the Orgueil meteorite, one section of the Murchison meteorite and one section of the Paris meteorite provided by the Muséum National d'Histoire Naturelle (Paris). They were chosen to test the robustness of the method on different objects and also because they are extensively described previously in the literature. The Orgueil meteorite is an extensively altered CI chondrite (Scott \& Krot, 2003). This type of chondrite contains neither chondrules nor refractory inclusions and has generally been considered as pure matrix material. Orgueil is composed almost entirely of serpentine and saponite phyllosilicates and inclusions of ferrihydrite, magnetite, $\mathrm{Ca}-\mathrm{Mg}$ carbonate, and pyrrhotite as main minerals (Bostrom \& Fredriksson, 1965) (Nagy, Meinschein, \& Hennessy, 1963) (Nagy \& Andersen, 1964) (Bass, 1971) (Reid, Bass, Fujita, Kerridge, \& Fredriksson, 1970) (Kerridge \& Macdougall, 1976) (Tomeoka \& Buseck, 1988). The composition of Orgueil has been quantified by wet chemistry (Jarosewich, 1990) (Jarosewich, 2006) (Lodders, Palme, \& Gail, 2009) and falls close to the composition of the solar photosphere for all but the lightest and strongly volatile elements. This sample will allow us to validate the quantification method. Murchison is a CM2 chondrite which principally exhibits a mixture of Mg-serpentine with cronstedtite. Principal mineral inclusions identified are pyrrhotite, carbonate or sulfate, pentlandite, olivine and pyroxene (Kvenvolden, et al., 1970) (Barber, 1981) (Bernatowicz, et al., 1996). Murchison is a partially altered sample (Clayton \& Mayeda, 1984), but the matrix is exceptionally complex at the nanoscale and displays heavily aqueously altered minerals in close contact with anhydrous ones (Fuchs, Olsen, \& Jensen, 1973) (Mackinnon, 1980) (Mackinnon \& Zolensky, 1984) (Le Guillou, Bernard, Brearley, \& Remusat, 2014) (Trigo, Vila-Ruaix, Alonso-Azcárate, \& Abad, 2017). The Paris meteorite (CM2 chondrite) exhibits two lithologies of different alteration degree (Hewins et al., 2014). The least altered matrix areas 
consist mostly of amorphous silicate grains with abundant porosity which enclose numerous Fe-sulfide nanograins but also crystalline $\mathrm{Mg}$-silicates (forsterite and enstatite), Ni-rich sulfides and carbonaceous material (Marrocchi, Gounelle, Blanchard, Caste, \& Kearsley, 2014) (Leroux, Cuvillier, Zanda, \& Hewins, 2015) (Vinogradoff, et al., 2017) (Vacher, Marrocchi, Verdier-Paoletti, Villeneuve, \& Gounelle, 2016) (Piani, Yurimoto, \& Remusat, 2017). In more aqueously altered areas, the matrix consists mostly of a mixture of amorphous material and Fe-rich, crystalline phyllosilicates. The porosity fraction is less abundant and the mixed amorphous-fibrous material frequently forms a continuous groundmass (Leroux, Cuvillier, Zanda, \& Hewins, 2015) (Pignatelli, Marrocchi, Mugnaioli, Bourdelle, \& Gounelle, 2017). This sample will allow us to assess how much the density variation affects the quantification of composition.

Those samples have been embedded in an epoxy resin, mechanically polished and coated by a thin carbon layer $(\sim 10-15 \mathrm{~nm})$. Sections were first examined by optical microscopy and SEM in order to select areas for EDX mapping. Matrix was distinguished from fragments of chondrules, CAIs and other components by their distinctive sizes, shapes, and textures. Suitable matrix zones for EDX were selected in regions without wide fractures and without relief due to differential polishing.

Seven areas are studied in this paper. Areas in Murchison and Orgueil have been selected by choosing mineral distributions representative of the whole sample. Conversely, in the case of the Paris meteorite, different areas have been chosen as a function of their degree of alteration.

\subsection{Analytical conditions}

\subsubsection{Scanning electron microscopy}

The first objective is to enhance the spatial resolution of the analyses in order to reach the sub-microscale of grains in chondrite matrices. During EDX acquisition the X-ray generation volume is directly linked to the electron accelerating voltage. The lateral and depth resolution are improved as the accelerating voltage is reduced. In the case of fine-grained materials such as matrices of primitive chondrites, the decreasing of the electron accelerating voltage significantly improves the minimum grain size detectable. Various experimental conditions have been tested to reach an equilibrium between a maximal number of counts, a minimal X-ray volume interaction, a sufficient peak to background ratio of useful X-ray lines and an area sufficiently large to be representative of the whole sample. An accelerating voltage of $5 \mathrm{keV}$ was chosen with a probe current of $1.2 \mathrm{nA}$ to limit potential damage under the beam. However, reducing the accelerating voltage gives rise to two important issues: i) The number of counts is much lower than that obtained with conventional working conditions of $15 \mathrm{kV}-20 \mathrm{kV}$. ii) For a number of elements of interest, the K-series is not excited at low voltage (here $5 \mathrm{keV}$ ) or has significantly lower intensities. Elements with their K-line higher than the acceleration voltage see only their L-lines excited. This is the case for $\mathrm{Fe}-\mathrm{Ti}-\mathrm{Ni}-\mathrm{Cr}-\mathrm{Mn}$ and requires us to work only on those lines which are concentrated below a few keV. For these elements, we used the L-alpha lines and a Gaussian deconvolution procedure to measure intensities. This approach will be discussed in more detail in the next section (3.4).

Hyperspectral maps were acquired using a FEG-SEM JEOL JSM-7800F LV at the University of Lille equipped with an EDX/EBSD Aztec system from Oxford Instruments and a silicon drift detector (SDD $\mathrm{XMaxN}$ ) of $80 \mathrm{~mm}^{2}$. The development of field emission gun (FEG) sources over the past 25 years has permitted the production of electron beams which are smaller in diameter, more coherent and with greater current density. Thanks to this technical improvement, hyperspectral map can be performed with lower accelerating voltage in order to resolve small grains while maintaining a sufficient X-ray signal, an adequate peak to background ratio and a relatively short acquisition time. 
All hyperspectral EDX maps were collected with an acquisition time of about 12-14 hours including a dead time of $18 \%$, a mean input count rate of $50000 \mathrm{cps}$ and an output of $40000 \mathrm{cps}$. We set a process time of 3 on the Aztec software in order to obtain a full width at half maximum (FWHM) of the manganese K $\propto$ peak of $135 \mathrm{eV}$ for the different maps. Monte Carlo simulations were performed using NIST-DTSAII software (Ritchie, 2009) to estimate the interaction volume at $5 \mathrm{keV}$. Depth resolution variations with those conditions are contained in a range between 100 nanometers (for Fe-rich metal grains) and up to $~ 300$ nanometers (based on the Fe L-alpha line) for porous phyllosilicates (compared to $300 \mathrm{~nm}$ and $1.5 \mu \mathrm{m}$ respectively for a $15 \mathrm{keV}$ accelerating voltage). Again the comparison of the probed volumes is interesting: it is contained between [0.003 - $0.040 \mu \mathrm{m} 3$ ] for the $5 \mathrm{keV}$ conditions while the range becomes [0.3 $-10 \mu \mathrm{m} 3$ ] for the 15 $\mathrm{keV}$ conditions (also based on the Fe L-alpha line). The resolution of X-ray maps has been defined by the width of the interaction volume. Pixel size is then fixed to $260 \mathrm{~nm}$ to avoid over-sampling and such that each interaction volume is always approximately contained in one pixel. Each map consists of a typical rectangular matrix of 1024 by 832 pixels corresponding to a region of $270 \mu \mathrm{m}$ by $220 \mu \mathrm{m}$. A working distance of $10 \mathrm{~mm}$, a dwell time of $200 \mu \mathrm{s}$, and an energy range of $10 \mathrm{keV}$ for 2048 channels $(5 \mathrm{eV}$ per channel) were used. The total number of counts obtained with those conditions was typically 1-2 billion in the whole map, which corresponds to 1500 - 2000 counts per pixel and to 125 summed frames. During acquisition, a drift correction was used, based on a BSE image with double the size of the analyzed region. After the acquisition the maximum drift correction recorded was $750 \mathrm{~nm}$, with a mean drift of $230 \mathrm{~nm}$ (i.e. about one pixel).

\subsubsection{Electron probe microanalysis}

To reduce errors during EPMA and obtain precise compositions, new standards have been carefully mounted. A series of standards provided by the Smithsonian Institution, Department of Mineral Sciences and by the SARM (Service d'Analyse des Roches et des Minéraux), have been used (fayalite, diopside, hornblende, biotite, siderite, magnetite, and plagioclase samples). Major and minor element concentrations were measured by a CAMECA SX 100 at the University of Lille, using an accelerating voltage of $15 \mathrm{keV}$ and an intensity of $10 \mathrm{nA}$ for most minerals, and slightly defocused $(3 \mu \mathrm{m})$ for carbonates and phyllosilicates which are more sensitive to the electron beam.

$\mathrm{K} \propto$ peak intensities for $\mathrm{Si}, \mathrm{Al}, \mathrm{Na}$ and $\mathrm{Mg}$ were collected on a TAP crystal, the $\mathrm{Fe}, \mathrm{Ni}$ intensities on a $\mathrm{LiF}$ crystal and other elements $\mathrm{K}, \mathrm{S}, \mathrm{Ca}, \mathrm{P}, \mathrm{Ti}, \mathrm{Cr}$ on a LPET crystal. The oxygen concentration was calculated by stoichiometry. We used a counting time of 20 seconds to obtain quantitative point analysis for all elements but a loss compensation model has been applied to the $\mathrm{Na}$ and $\mathrm{K}$ intensities. The background subtraction has been achieved by averaging the bremsstrahlung counts in two identical windows on either side of the characteristic peaks. In few cases, one of the two windows was inaccessible due to another peak. In that case only, one window has been used and a slight slope (between 1 and 1.2) is used to compensate the lack of the other window. 


\section{Analyzing the Composition, the modal Abundance and the Density using Electron MicroscopY (ACADEMY)}

We used low-voltage EDX hyperspectral maps combined with EPMA and established a method to obtain modal abundance, density maps and bulk composition of heterogeneous phase assemblages.

The procedure can be divided into five parts steps which are summarized in Fig. 1. These steps include background modelling and peak fitting of EDX spectra, phase map, EPMA chemical quantification, density map and quantification.

- Elemental maps were created from the raw EDX hyperspectral data thanks to the development of a background model which is fitted together with Gaussians for the different X-ray lines.

- Elemental maps were analyzed by a classification algorithm in order to obtain a high-resolution phase map. Linear combination of end-member spectra was used to account for mixing of grains smaller than the pixel size. We thus obtained accurate modal abundances.

- These data were turned into quantitative maps using EPMA data as calibration.

- The density of each phase was determined by analyzing the bremsstrahlung background, which is a function of density. Determining the density is a requisite for obtaining bulk composition.

- The bulk composition of the entire region of mixed fine-grained materials was calculated by combining modal abundance, phase composition and density information.

Most data are processed using Hyperspy, an open source library for analysis of multidimensional data (De la peña, et al., 2017). A first phase classification is performed using XmapTools (Lanari et al., 2014) and corrected afterwards by manual thresholding. The background modeling approach has been implemented in HyperSpy and can be performed automatically on any dataset. A script allowing to reproduce the whole procedure is available at: https://github.com/ZanettaPM/Demo-ACADEMY.

Fig 1: ACADEMY operating diagram schematizing the structure of the method. The final result of the entire method is the convolution of resulting parameters to obtain the local and global quantitative chemistry.

\subsection{Background modeling and spectrum fitting strategy}

SEM-EDX spectra are characterized by an important background, especially at energies below $2.5 \mathrm{keV}$ and it was necessary to develop a background model including bremsstrahlung to obtain accurate peak intensities for weakly abundant elements.

To model the background, two different phenomena must be considered, the bremsstrahlung emission and the $\mathrm{x}$-ray absorption in the sample and the detector (eq. 1). The bremsstrahlung phenomenon generates X-rays as a result of the deceleration of electrons due to the Coulombic fields of the different atoms. Then, this radiation is absorbed within the sample (Statham P. J., 1976) (Small, Leigh, Newbury, \& Myklebust, 1987). In our model, we combined physical expressions of these phenomena from different sources. Continuous Xray emission by a thick target is modelled using electron scattering cross sections by the ThomasWhiddington law (Kramers, 1923).

$$
I_{B r}=K Z \frac{\left(E_{0}-E_{v}\right)}{E_{v}}
$$

where $\mathrm{I}_{\mathrm{Br}}$ is the intensity produced by the energy of the incident electrons $E_{0}, E_{v}$ is the energy of the bremsstrahlung $\mathrm{x}$ rays, $\mathrm{K}$ is Kramer's constant, and $\mathrm{Z}$ is the mean atomic number of the ionized atoms. Absorption of the emitted X-rays within the sample and the detector are taken into account based on (Statham P. J., 1976) (Ritchie, 2009). The theoretical absorption correction $F$ can then be written as: 


$$
\mathrm{F}(\chi)=\int_{0}^{\infty} \varphi(\rho x) e^{(-\chi \rho x)} d \rho x
$$

where $\rho$ is the density, $x$ the depth, $\varphi(\rho x)$ is the ionization density as a function of depth, $\chi=\mu / \rho * \sin (\theta)$, with $\mu / \rho$ the mass absorption coefficients and $\theta$ the take-off angle. A simplified model (square model) has been proposed by (Sewell, Love, \& Scott, 1985) that allows the simplification of the $\varphi(\rho x)$ distribution term. A top-hat profile representing the mean value of the distribution of the X-ray emission is assumed. This simplification allows one to consider a constant distribution which does not depend on the depth. We used their formulation:

$$
I_{\mathrm{Br}}=\mathrm{KZ} \frac{\left(E_{0}-E_{v}\right)}{E_{v}} * \frac{1-\mathrm{e}^{-2 \chi \rho \mathrm{x}}}{2 \chi \rho \mathrm{x}} * \mathrm{C} * \mathrm{~W}
$$

The parameters $\mathrm{C}$ and $\mathrm{W}$ represent the absorption taking place in the thin-layer coating of the sample and in the polymer window of the EDX detector, respectively. The mass absorption coefficients, which are function of energy, can be calculated according to:

$$
\mu / \rho(\mathrm{E})=\sum_{i=1}^{n} W_{i} \mu_{i}
$$

where $\mathrm{W}_{\mathrm{i}}$ and $\mu_{\mathrm{i}}$ are the weight fraction and mass absorption coefficients for element $\mathrm{i}$ in a compound with $\mathrm{n}$ elements. We used the mass absorption coefficients database of Chantler et al. (2005). Weight fractions are known a priori, and two options are available in the Hyperspy module of our model: i) by default, weight fractions are estimated by integrating EDX peaks or ii) when they are known, the phase compositions can be provided as inputs to obtain a more precise model (see section 3.3).

Absorptions due to the thin coating layer (C) and by the polymer window (W) must be taken into account because the efficiency of low-energy X-ray collection has a major impact on background modeling. The coating layer parameter is computed using the Love and Scott model:

$$
\mathrm{C}=\frac{1-\mathrm{e}^{-2 \chi \rho x}}{2 \chi \rho \mathrm{x}}
$$

We used values for $\rho$ and $\mathrm{x}$ of $1.9 \mathrm{~g} / \mathrm{cm}^{3}$ and $15 \mathrm{~nm}$ for the sample coating (100 wt\% of C). For the W parameter we used the ultra-thin polymer window curve proposed in (Schlossmacher, Klenov, Freitag, Harrach, \& Steinbach, 2010). The two main absorption edges are the carbon absorption edge $(280 \mathrm{eV})$ and the oxygen edge $(520 \mathrm{eV})$. The minor absorption edge below $2 \mathrm{keV}$ is due to the thin aluminum coating used for the UV, IR and visible light rejection. (see supplementary materials 1 )

The unknowns which must be fitted are "KZ" and the mass depth ' $\rho x$ '. $\mathrm{K}$ is a constant for all pixels in a given hyperspectral map. The KZ value could be perfectly fitted using the higher energy range of the spectra (> 2.5 keV, Fig.2), where absorption is negligible (Statham, Penman, \& Duncumb, 2016). The mass-depth parameter ' $\rho x$ ' is fitted on the low energy part of the spectrum $(<2.5 \mathrm{keV})$.

Fig 2 Gaussian fitting and background modeling using Hyperspy. The first spectrum is Galena measured with a $5 \mathrm{keV}$ accelerating voltage while the second spectrum is chalcopyrite measured at $15 \mathrm{keV}$. The background is modeled at two different beam energies. Each pixel/spectrum of the hyperspectral map was fitted using this background model. 
We fitted the data using a linear combination of the different components (i.e background and Gaussians) and a least square minimization method (Fig.2). Net peak counts are given by the Gaussian areas which allows us to obtain maps for 12 elements: $\mathrm{C}, \mathrm{O}, \mathrm{Na}, \mathrm{Mg}, \mathrm{Al}, \mathrm{Si}, \mathrm{P}, \mathrm{S}, \mathrm{K}, \mathrm{Ca}, \mathrm{Fe}$, and $\mathrm{Ni}$. At $5 \mathrm{keV}$, for some elements, only the $\mathrm{L}$ lines are available $(\mathrm{Fe}-\mathrm{Ni})$. These lines are present at low energy (below $1 \mathrm{keV}$ ) and their deconvolution can sometimes be ambiguous. Some elements were below detection level, such as $\mathrm{Ti}-\mathrm{Cr}-$ Mn (but were accessible by EPMA; see section 3.3). 


\subsection{Phase mapping and modal abundances}

\subsubsection{Phase recognition and pixel classification}

The phase map is established in two steps. The first one consists of identifying the various phases present using compositional fields. It is a "training stage" which is necessary to define "reference" grains. The second step uses those reference grains for the supervised classification of all pixels, performed thanks to the XMapTools software (Lanari et al., 2014). The X-ray intensities are plotted to reveal compositional endmembers and mixing lines (Fig. 3A). Those composition fields are directly extracted from the elemental count map, where each datapoint corresponds to one pixel. Each cluster represents a phase of a given composition (but from randomly distributed grains). We use these plots (Matlab®) to select pixels of similar composition and reveal the localization of the different "objects" (minerals, mineral boundaries and fractures).

In an $\mathrm{Mg}$ vs. Si plot (Fig. 3A), pixels with high $\mathrm{Mg}$ counts correspond to forsterite and enstatite (all phases are confirmed by later EPMA quantification, see section 3.3). The sharp boundaries of grains match with the BSE images and exhibit a geometry typical of fragmented silicate inclusions found in chondrite matrices (Fig. 3B). Pixels of intermediate compositions (Fig 3.C) correspond to finer scale mixtures of amorphous silicates and phyllosilicates with other embedded grains such as sulfides. There are more chemical heterogeneities in these clusters and their limits are not as clear as for single crystals. It is known that phyllosilicates in primitive chondrites are commonly serpentines, a family of minerals showing a solid solution series between Fe and Mg end-members (Tomeoka \& Buseck, 1985) (Zolensky, et al., 1997) (Lauretta, Hua, \& Buseck, 2000). In order to better describe this solid solution, we defined two end-members, an Fe-rich fraction and an Mg-rich fraction. Pixels between the two clusters of Fig 3.B and 3.C exhibit intermediate compositions and correspond to the boundaries of anhydrous silicates (i.e. where the beam probes two different phases) or to mixing of grains smaller than the pixel size. Pixels low in both $\mathrm{Mg}$ and $\mathrm{Si}$ (Fig.3.D) correspond to phases such as troilite, pentlandite, carbonate or metal and can be identified using other composition fields ( $\mathrm{Fe}, \mathrm{S}, \mathrm{Ca}$ and $\mathrm{Ni}$ ). The BSE map acquire simultaneously to the X-ray data can also be plotted in composition field versus the different elements since it contains a mean $\mathrm{Z}$ information, but also give a spatial information (grains location, boundaries etc.).

Fig 3: A: X-ray intensities of $\mathrm{Mg}$ and $\mathrm{Si}$ peaks, combined with Fe intensity (colorbar). Each point corresponds to one pixel (Paris Zone 2). Pixels of identical composition form clusters. B: forsterite and enstatite map based on the selection of the corresponding cluster. C: This cluster corresponds to a fine-grained mixture of amorphous silicates, phyllosilicates with sulfides and anhydrous silicate inclusions. $\mathrm{D}$ : Map of the remaining pixels after thresholding for $\mathrm{Mg}$ and $\mathrm{Si}$. This selection contains $\mathrm{Mg}$ and $\mathrm{Si}$-free phases, such as metal grains, sulfides, etc. Unselected pixels are displayed as a secondary electron image or back-scattered electron image.

We used the XMapTools software to build phase map (Lanari, et al., 2014). However, this classification could also be done using open source python libraries. XMapTools is a MATLAB@-based graphical user interface dedicated to electron microprobe X-ray image processing (Lanari, et al., 2014). It uses K-means clustering to classify pixels into classes of similar compositions. The K-means procedure identifies clusters and allocates pixels to these clusters by minimizing the distance in the compositional space between each pixel and the center of gravity of each cluster (Saporta, 2006). As for other supervised classification methods, the user needs to define reference pixels as initial guesses for each group on the chemical map. The compositions of these pixels are used as starting cluster centroids.

Fig 4: Phase map of the matrix of the Paris meteorite (Zone 2) after manual adjustment; 11 different phases were found. Grains down to 500 nanometers are visible and well classified. 
We chose to use the "normalization" function which considers the mean values of the elemental maps such that all elements have the same weight and only the variances are compared. A map is generated displaying the principal phases, which have higher abundances and largest chemical differences between them (Figure 4). Regions of anhydrous silicates, phyllosilicates, fractures and sulfides are clearly revealed.

However, phases represented by only a few pixels and weak chemical difference in comparison to some other more abundant phase are neglected most of the time. After the first map proposed by XMapTools it is necessary to go back to the composition field step, to manually check that no artefacts have appeared and add new phases, whenever appropriate. This step allows separating into two phases pixels which may have been mistakenly grouped together. It produces maps that are more accurate but it does not change the modal abundances, which only depends on the MLLS procedure (see next section).

\subsubsection{Fitting linear combination of spectra to unravel phase mixing at the pixel scale}

It has been shown that matrices of carbonaceous chondrite are made of a heterogeneous assemblage of grains smaller than $1 \mu \mathrm{m}$ which cannot be resolved with a pixel size of $300 \mathrm{~nm}$. To refine the modal abundance determinations, we deconvolved spectra of mixed fine-grained materials using linear combination of "end-member" spectra. Reference spectra were defined by considering only the pixels from the center of the clusters which are considered as "pure" (Fig.3.A). A non-negative linear combination is fitted using Hyperspy by scaling coefficients (mixing proportions) to the experimental spectrum by means of least-square optimization (Leapman \& Swyt, 1988) and can be expressed as the following formulation.

$$
E s=\sum_{j=1}^{n}\left(\alpha_{j} * \operatorname{Sref}_{j}\right)
$$

Where Es is the experimental spectrum, $\alpha$ are mixing coefficients, Sref are the spectra of the end-members and $\mathrm{j}$ is the number of phase. We used the denomination "MLLS" for "Multiple Linear Least Square fitting" to refer to this procedure.

Fig 5: Example of a MLLS deconvolution. A: Map of the proportion of the Mg-rich phyllosilicate in the fine-grained matrix. B: Modal abundances before and after correction provided by the MLLS fitting. Forsterite olivine has Mg>98\% while ferroan olivine has typically around $15 \%$ of $\mathrm{Fe}$

This step led to significant improvements of the modal abundances. About $25 \%$ of the total volume initially classified as "Fe rich phyllosilicates/amorphous silicates" was re-assigned to other phases. In contrast, the abundances of sub-micrometer grains of pyroxenes, olivine and sulfides embedded within the "phyllosilicate/amorphous silicates" were initially under estimated. However, the fact that the amorphous/phyllosilicate material contains a low amount of S can be problematic. The deconvolution of the nano-sulfides will be based on the variation of a peak with a small number of counts. This weak count statistic is visible in Fig 5.B, and the modification by the MLLS step of the abundance of sulfides is relatively small compared to what can be expected from TEM studies (Zolensky, Barrett, \& Browning, 1993) (Brearley, 2006) (Leroux, Cuvillier, Zanda, \& Hewins, 2015). This poor constrain on the S peak can lead to an underestimation of the nano-sulfides and impacted the final matrix composition. 
Table 1: modal abundances obtained with phase map in the matrix of the Paris meteorite (zone 2) and associated relative error due to the variation of the mixed phase proportions among the different pixel of the map.

Errors in the attribution have been estimated by the means of the multinomial statistic law (Dirichlet law). Only pixels for which the non negative constraint imposed by the MLLS fitting had a very low impact (around $85 \%$ of the fine matrix), and therefore when the statistic $\chi^{2}$ law was applicable, were considered. The modal abundances given by the MLLS procedure correspond to a mean value. This mean value is calculated based on the proportion of the different phase in each pixel. In order to calculate the error in the attribution, we calculate the standard deviation around these mean values for the considered pixels. For a random mixing and a sufficient number of pixel, the standard deviation should be low and the value of most of the pixels should draw near the mean value. We make the assumption that the deviation is therefore linked to an error in the attribution of the different phase by the MLLS procedure.

Table.1 represents the relative error compared to the abundance of the phase. This estimation leads to errors below $3 \%$ for most of the phases. Phyllosilicate which has the most varied proportions in the whole map has the largest error. The standard deviations for the Mg-rich part and the Fe-rich part of the fine material have been calculated separately since two clear population of the mixture could be distinguished. The coarse grains previously masked are considered to be perfectly attributed to the right class and we assume that their errors are negligable. Thanks to the low-voltage of the acquisition and the high resolution of the map, errors stay below a few percent (8-12\%) and seem appropriate for fine-grained material application.

\subsection{Quantitative chemical calibrations by EPMA}

In order to obtain quantified compositional maps, we coupled the high spatial resolution maps obtained by SEM-EDX with EPMA. We use the phase map to identify the largest grains of each different phases and use them as an internal calibration. Reference grains were selected as follows: 1) They have to be large enough for the EPMA probe $(>2-3 \mu \mathrm{m}), 2)$ they have to correspond to pixels from the center of the clusters (i.e. endmembers). Numerous EPMA standards were prepared in order to be as close as possible to the chemistry and the density of the phase to quantify. In particular, an iron-rich biotite (ref: 12:119-201 (Govindaraju \& Roelandts, 1988)) was used for the Mg-Fe-Si quantification of the amorphous/phyllosilicate material, since they have $\mathrm{Fe} / \mathrm{Si}=0,56$ and mean density of $3 \mathrm{~g} / \mathrm{cm}^{3}$ which are close to each other, a point which is crucial for precise absorption correction calculation.

The effect of the water contained in the amorphous/phyllosilicate material has also been taken into account for quantification. Bulk water content values have been taken from (Jarosewich, 1990) (Jarosewich, 2006) for Orgueil and Murchison and from (Vacher, Marrocchi, Verdier-Paoletti, Villeneuve, \& Gounelle, 2016) for Paris. We made the assumption that most water is carried by the amorphous/phyllosilicate material, which contains $18.3 \% \mathrm{H}_{2} \mathrm{O}$ (wt. \% oxide) for Orgueil, 18.2 wt. \% for Murchison and 17.5 wt. \% for Paris. These values have been added to the quantification sheets of the phyllosilicate reference grains in the EPMA software to allow accurate $\varphi(\rho z)$ correction.

We identified that the principal source of error in the EPMA results is the counting statistic which depends on the concentration of each element, with the error ranging from $\sim 0.4 \%$ for $\mathrm{Mg}$ to $15 \%$ for $\mathrm{Na}$ in olivine (see supplementary material 2). We minimized other errors by carefully defining our working conditions according to (Lifshin \& Gauvin, 2001). 


\subsection{Density determination through bremstrahlung modelling}

\subsubsection{Validation of the method using reference materials}

Bremsstrahlung is a function of the material density and modelling and fitting it can therefore be used to determine the density of a material based on its EDX spectrum (see section 3.1). However, the proxy obtained by curve fitting is the mass-depth (i.e. $\rho x$ ) and not directly the density itself. In order to determine the respective contribution of the density and the emission depth, which are non linearly coupled, we used standards covering a large range of compositions and densities. The following standards were measured at 5 and $15 \mathrm{keV}$ : Albite, Almandine, Anhydrite, Apatite, Arsenopyrite, Barite, Benitoite, Biotite, Calcite, Chalcopyrite, Chlorite, Chromite, Diopside, Dolomite, Galena, Hematite, Jadeite, Magnetite, Olivine Orthoclase (see supplementary material 3). For background modelling, the absorption correction relies on the estimation of the phase composition. Here, instead of estimating composition based on peak fitting as done for unknown materials (see section 3.1), we used the composition of the standards as direct inputs to be as accurate as possible.

Fig 6: Plots of the ' $\rho x$ ' proxy obtained by least square minimization of eq. (4) versus the real density of the standards.

Our results demonstrate that the fitted $\rho x$ parameter is correlated with density (Fig. 6) and thus that background modelling allows the determination of the density of unknown samples (Fig. 7) whereas the emission depth only induces second order variations. We obtain a mean absolute percentage error (MAPE) of $10 \%$ for the $5 \mathrm{keV}$ conditions and $24 \%$ at $15 \mathrm{keV}$ (Fig.6). Errors related to the fitting procedure are negligible. At $5 \mathrm{keV}$, the correlation is better because interaction volumes decrease at lower voltage and thus, for the same density range, the variability of the emission depth is smaller. The principal uncertainty is the variability of the emission depth. Indeed, based on Monte-Carlo simulations, the variations of mean emission depth at $5 \mathrm{keV}$ can be around 20\% (Ritchie, 2009). Nonetheless, uncertainties on the mass absorption coefficients and approximation linked to the chosen model might also have a strong effect on the background modelling. At low energy (below $1 \mathrm{keV}$ ), values of mass attenuation coefficients found in different databases (Heinrich, 1986) (Henke, Gullikson, \& Davis, 1993) (Chantler, et al., 2003) are poorly constrained which could explain part of the uncertainties. This parameter is critical in many aspects of modeling X-ray transport and the improvement of these databases is necessary (Lepy, Mantler, \& Beckhoff, 2008). Conversely, the background model is an evolutionary code which could be easily improved in the future. For instance, montecarlo simulations could be implemented for the determination of the X-ray emissions allowing to not use the Love \& Scott simplification anymore.

\subsubsection{D density and porosity mapping of heterogeneous assemblages}

In chondrites, the density of fine-grained regions, made of a porous mixture of amorphous silicate, phyllosilicates and sulfides, is unknown. In this case, we then used the known density of the surrounding phases (Troilite, Pentlandite, Olivine..., including the epoxy which embed the samples) to establish an internal calibration. We obtained an excellent correlation with a mean absolute percentage error of MAPE $=8 \%$ which allows us to determine the density of the amorphous/phyllosilicate regions (Fig. 7.A) and to produce a density map (Fig. 7.B).

Fig 7: A. Mean proxy values (Paris zone 2) for all pixels of each different phase versus their nominal density. The error bars represent the mean absolute error $(\mathrm{MAE}=0.41)$ calculated in the previous section. $\mathbf{B}$ : resulting density map produced by this approach. 
The mean density of the amorphous/phyllosilicates mixed with nano-inclusions is $2.9 \pm 0.32 \mathrm{~g} / \mathrm{cm} 3$ for the Fe-rich part and $2.8 \pm 0.31 \mathrm{~g} / \mathrm{cm} 3$ for the $\mathrm{Mg}$-rich part. Considering the abundance of sulfide nano-inclusions the iron content of the phyllosilicate and the nano-porosity, these values are coherent.

From this result it is possible to calculate the density of the phyllosilicate itself without the contribution of the other phases. We calculated a mean density map of the inclusions based on the MLLS results:

$$
D_{\text {inclu }}=\sum_{j=1}^{n}\left(\alpha_{j} * D_{\text {nom } j}\right)
$$

Where $\alpha$ are mixing coefficients, $D_{\text {nom }}$ is the nominal density of the different phases and $j$ the number of inclusions embedded in the phyllosilicate material. The difference between the density map calculated using background modeling and the density of inclusion phases gives a residual. This residual represents the density of the phyllosilicate material with a variable amount of porosity.

$$
D_{\text {Phyll }}=\frac{D_{A p p}-D_{\text {Inclu }}}{\alpha_{\text {phyll }}}
$$

Where $D_{\text {app }}$ is the apparent density found thanks to the background modeling and $\alpha_{\text {phyll }}$ is the mixing coefficient of the Fe-rich and Mg-rich amorphous/phyllosilicate material. Values found for Paris are 2.35 $\mathrm{g} / \mathrm{cm} 3$ for the $\mathrm{Mg}$-rich part and $2.44 \mathrm{~g} / \mathrm{cm} 3$ for the iron rich part. Now, if a nominal density of $2.8 \mathrm{~g} / \mathrm{cm} 3$ for the Fe-rich part and $2.6 \mathrm{~g} / \mathrm{cm} 3$ for the $\mathrm{Mg}$-rich part (deduced from their Fe/Mg ratio) is assumed and if all the porosity is considered to be filled by epoxy, then, mean porosities of $22 \%$ and $18 \%$ are needed to explain respectively the apparent density of the Mg-rich part and the Fe-rich part (see supplementary materials 4).

\subsection{Calculation of the bulk composition and related uncertainties}

We combine the modal abundance, the chemical composition and the density of each phase to calculate the bulk composition of the analyzed region using the following equation:

$$
[I]=\sum_{j=1}^{n}\left(M_{j} *[I]_{j} * \rho_{j}\right)
$$

where $I$ is the concentration of a given element, $\mathrm{j}$ a given phase, $\mathrm{n}$ the number of phases, $\mathrm{M}$ is the abundance of a phase in vol.\%, and $\rho$ is the density. The area abundances have been directly converted into volume fractions according to (Cuzzi \& Olson, 2017). The density used for the known phases (olivine, pyroxene, etc..) are taken from the literature (accounting for their compositions) whereas the density for the amorphous/phyllosilicate phase is determined based on background modelling. By computing each relative error previously discussed, we can also determine an associated error. We first determined a relative error per phase and per element to obtain afterwards errors on the global composition (table.3).

Table 2: Bulk composition of the matrix of Paris in at $\%$. Absolute errors linked to the entire method are indicated in percent for the Paris meteorite (zone 2).

Large uncertainties are found for elements with minor concentrations ( $\mathrm{Ti}, \mathrm{P}, \mathrm{K}, \mathrm{Na}, \mathrm{Cr}$ ). This is due to the low counting statistics of EPMA acquisition. Conversely, the errors for major elements (i.e. $\mathrm{Mg}, \mathrm{Fe}, \mathrm{Si}$ ) depend on the modal abundance error and the density error. Indeed, the amorphous/phyllosilicate domains which carry a large fraction of these elements, display tortuous edges, mixing of phases and are heterogeneously porous. 


\section{Applications of ACADEMY to fine-grained assemblages from chondrite matrices}

\subsection{Density, modal abundances and bulk composition}

We applied ACADEMY to several areas $(220 * 270 \mu \mathrm{m})$ of the Orgueil, Paris and Murchison chondrites. Different areas in Paris have been selected because they display different degrees of alteration: zone number 2 is located in a fresh area where chondrules exhibit large metal grains with only thin oxidized rims on their borders. Zone 3 is located in a more aqueously altered area showing phyllosilicates. Zone 1 is intermediate between the zones 2 and 3 .

Fig 8: Phase map (top), and density map (bottom) are displayed. Three matrices of different meteorites are compared: A: Orgueil; B: Murchison; and C: Paris Zone 1. Each map consists of region of $270 \mu \mathrm{m}$ by $220 \mu \mathrm{m}$.

ACADEMY allows us to quantitatively compare modal abundances of heterogeneous matrices (Fig.8 and 9). In the case of Zone 1 and Zone 2 of the Paris meteorite, large chondrule fragments were ignored. Matrices are dominated by a mixture of amorphous silicates and phyllosilicates that ranges from $55.7 \pm 5.9 \%$ in Paris, $67.0 \pm 7.1 \%$ in Murchison and up to $94 \pm 9.9 \%$ in Orgueil. Conversely, anhydrous silicates represent $14.1 \pm 0.2 \%$ of the matrix of Murchison and reach $23.0 \pm 0.6 \%$ for the unaltered part of the matrix of Paris $(0 \%$ in Orgueil). In Paris, the amount of amorphous silicates/phyllosilicate varies between $49.1 \pm 5.2 \%$ for the unaltered parts and $62.8 \pm 6.7 \%$ for more altered regions. Also, anhydrous silicates vary from $23 \pm 0.6 \%$ to $21 \pm 0.3 \%$ between these two regions respectively (see supplementary material 5).

The mean density of the phyllosilicates mixed with nano-phases varies from $2.60 \mathrm{~g} / \mathrm{cm}^{3}$ for Paris to 3.15 $\mathrm{g} / \mathrm{cm}^{3}$ for Murchison and $3.24 \mathrm{~g} / \mathrm{cm}^{3}$ for Orgueil. The accuracy is lower for Orgueil since there was not as many phases of known density available to establish the internal calibration. Paris has a more heterogeneous and higher density than Orgueil (Fig. 8).

Fig 9: Modal mineralogy of the different matrices as determined by phase mapping and MLLS fitting. For phases other than phyllosilicates, relative errors range from 0.5 to $3 \%$. This error is larger for phyllosilicates (8-12 \%). Zones with a symbol ' $*$ ' indicate areas from which large chondrule fragments were ignored (see supplementary materials 6 ).

Finally, we calculated the matrix bulk composition for the three meteorites. The deduced composition falls close to chondritic values and deviations in major elements $(\mathrm{Mg}-\mathrm{Si}-\mathrm{Fe})$ are small. A stronger variability is observed for mobile elements (Ca, S, K and $\mathrm{Na}$ ).

Fig 10: Bulk compositions of matrices (atomic ratios) calculated by ACADEMY (average of all analyzed regions) normalized to silicon and to the composition of Orgueil determined by wet chemistry (Lodders \& Palme, 2009). (See supplementary materials 7)

\subsection{Comparison to wet chemistry and EPMA data}

\section{ACADEMY compared to wet chemistry for Orgueil}

Orgueil is the only meteorite for which the bulk composition of the matrix has been quantified by wet chemistry (Jarosewich, 1990) (Jarosewich, 2006) (Lodders, Palme, \& Gail, 2009). A good correlation is found between the wet chemistry and ACADEMY values (R2 0.96; Fig. 11). Considering major elements only, the match is even better. Deviations are mainly due to the scale of the analysis. Sulfides, carbonates and phosphates, which occur as large patches and are not perfectly sampled at this scale, biases the concentrations of $\mathrm{Fe}, \mathrm{Ca}, \mathrm{P}$ and $\mathrm{S}$. We calculated that a depletion of $5 \%$ of sulfides and $1 \%$ of carbonates could explain the lower $\mathrm{Fe}, \mathrm{S}$ and $\mathrm{Ca}$ contents. For minor elements such as $\mathrm{K}, \mathrm{Na}, \mathrm{Cr}$ or $\mathrm{Ti}$, additional deviations could be 
linked to their low concentrations within their carrier $(<1$ at. \%) which leads to higher uncertainties. In the case of published EPMA measurements, a part of the deviation could also be due to non-representative sampling of carbonates and sulfides.

Fig 11. Bulk matrix compositions obtained by ACADEMY and EPMA compared to data obtained wet chemistry (Lodders, Palme, \& Gail, 2009). EPMA data are from (McSween Jr \& Richardson, 1977), (Zolensky, Barrett, \& Browning, 1993), (Zanda, Lewin, \& Humayun, 2018).

\section{The role of EPMA standard, water content and phase specific density weighing.}

In chondrites, because matrices and chondrules cannot be easily separated for independent measurement by wet chemistry, "bulk" matrix compositions have been mainly determined by EPMA using a defocused beam of five to a few tens of microns. Here we discuss the technical advantages of ACADEMY and we compare our matrix composition results to the EPMA data of previous studies.

Accurate quantification by EPMA requires: (1) performing $\varphi(\rho z)$ corrections on a homogeneous material, which becomes complicated when different phases are mixed together; (2) the use of specific standards that are chemically and in density close to the mineral to quantify; (3) all elements present in the sample have to be taken into account for the $\varphi(\rho z)$ correction, including hydrogen and oxygen from water. In addition, to obtain accurate bulk composition, the modal abundance of each phase has to be pondered by their density. In matrices of primitive chondrites, the infra-micrometric grains-size, the presence of water, and the variable densities precludes an ideal EPMA measurement, especially when a defocused EPMA probe is used.

To evaluate improvements due to these different parameters (Fig. 12), we compared the bulk Fe/ $\mathrm{Si}$ and $\mathrm{Mg} / \mathrm{Si}$ ratios: i) using two different EPMA standards to quantify the $\mathrm{Mg}-\mathrm{Fe}-\mathrm{Si}$ concentrations of the amorphous/phyllosilicate material; ii) by adding the water to the $\varphi(\rho z)$ correction (post-measurement); iii) weighting by the density of the different phases. Compared to previously published EPMA data, ACADEMY provides composition much closer to the wet chemistry data.

Fig 12. $\mathrm{Fe} / \mathrm{Si}$ and $\mathrm{Mg} / \mathrm{Si}$ (at. \%) ratios for the Orgueil meteorite obtained by previous results and compared to ACADEMY. The effect of different parameters on the results of ACADEMY are presented, i.e. the use of two different standards, the addition of $\mathrm{H}_{2} \mathrm{O}$ content for the $\varphi(\rho z)$ correction, and the density ponderation. These analytical improvements increases the $\mathrm{Fe} / \mathrm{Si}$ and the $\mathrm{Mg} / \mathrm{Si}$ ratio by about 22 and $12 \%$ respectively which are ultimately very close to the wet chemistry data (dashed line; from (Lodders \& Palme, 2009)). EPMA ratios are taken from (McSween Jr \& Richardson, 1977), (Zolensky, Barrett, \& Browning, 1993) and (Zanda, Lewin, \& Humayun, 2018).

Usually, EPMA measurements are obtained using standards such as Mg-rich silicate (forsterite or diopside) for $\mathrm{Mg}$ and $\mathrm{Si}$ and hematite for $\mathrm{Fe}$. Here, we compared a Mg-rich hornblende and a Fe-rich biotite and demonstrate that using the biotite improves the $\mathrm{Fe} / \mathrm{Si}$ and $\mathrm{Mg} / \mathrm{Si}$ ratios by about $7 \%$ and $10 \%$ respectively (Fig. 12). Iron in the amorphous/phyllosilicate material induces a differential absorption between the $\mathrm{Mg}$ and the Si peak which is not well corrected by the $\varphi(\rho z)$ procedure and leads to an underestimation of the $\mathrm{Mg}$ content. It is thus crucial to choose a standard which is chemically close to the targeted phase (i.e. the Fe-rich biotite).

One limit to analytical accuracy of the EPMA measurements of chondrites is that water and hydroxyl groups in the phyllosilicate are not taken into account (the "totals" never reaches 100\%). This underestimation of the oxygen content ultimately generates errors in the absorption corrections. By adding about $\sim 20 \% \mathrm{H}_{2} \mathrm{O}$ (wt.\% 
oxide) to the EPMA quantification procedure, the $\mathrm{Fe} / \mathrm{Si}$ and $\mathrm{Mg} / \mathrm{Si}$ ratios are improved by 1.5 and $2.6 \%$, respectively (Fig. 12).

Previous works have pointed out that EPMA data show deviations compared to bulk analytical methods because the quantification results are not balanced by the density of the different phases (Ichinokawa, Kobayashi, \& Nakajima, 1969), (Warren, 1997), (Nazarov, Ignatenko, \& Shevaleevsky, 1982), (Zanda, Lewin, \& Humayun, 2018). Thanks to the high resolution of the maps and because the different phases are considered independently, ACADEMY allows to apply a density ponderation as a final step. In Orgueil, the density ponderation improved the $\mathrm{Fe} / \mathrm{Si}$ ratio by about 13\% (Fig.12). This is due to the fact that iron is carried by various phases of different densities (sulfides and magnetites are denser than phyllosilicates). There is no improvement for the $\mathrm{Mg} / \mathrm{Si}$ ratio (Fig.12) since the phyllosilicates are the only carrier of this element in Orgueil.

\section{Comparison with previous works on Paris and Murchison}

Fig 13. Bulk matrix compositions obtained by ACADEMY and compared to EPMA data from (Zanda, Humayun, Barrat, Bourot-Denise, \& Hewins, 2011) for Paris, and (McSween Jr \& Richardson, 1977), (Zolensky, Barrett, \& Browning, 1993) for Murchison.

General trends are similar for both EPMA and ACADEMY (Fig. 11, 13) but compositions are generally closer to the chondritic value for ACADEMY. As for Orgueil, $\mathrm{Mg} / \mathrm{Si}$ and $\mathrm{Fe} / \mathrm{Si}$ ratio of Murchison and Paris fall nearer to the chondritic composition. Higher deviations are observed for mobile and/or volatile elements $(\mathrm{Na}, \mathrm{K}, \mathrm{Ca}, \mathrm{Fe}, \mathrm{S}$ ) which are susceptible to be in too low concentration, redistributed in the matrix or carried by small grains (i.e. Nanosulfides <150 nm (Barber, 1981) (Leroux, Cuvillier, Zanda, \& Hewins, 2015)). 


\section{Conclusions}

The ACADEMY method provides quantitative mineral maps with high spatial resolution of a few hundred nanometers (linked to the low-voltage X-ray emission volume) on representative areas for infer-micrometric assemblages. It presents several advantages: (1) Thanks to a high resolution and a thorough deconvolution procedure, it considers independently the different entities present in matrices; (2) it provides superimposed maps; (3) it permits a statistical analysis of the grains which constitute the region of interest (size distribution, circularity, Appendix 1.); (4) it provides a global composition taking into account the density parameter and allow to apply specific standards for the EPMA correction. This new method therefore appears to be most adapted for the analysis of micrometer-sized assemblages and has demonstrated its robustness for different samples of matrices of primitive chondrite.

Comparison to bulk wet chemistry data of Orgueil demonstrates that the $\mathrm{Fe} / \mathrm{Si}$ and $\mathrm{Mg} / \mathrm{Si}$ ratios given by ACADEMY are closer to the real composition than previously published EPMA defocused beam data. We found a deviation of $25 \%$ and only $1 \%$ respectively (compared to 35\% and $13 \%$ for defocused EPMA). Given that Paris and Murchison are more homogeneous in terms of grain sizes, densities and chemistry than Orgueil, the precision enhancements allowed by ACADEMY for their matrix measurement should be even larger (alternative data are not available at this point) which opens new avenues for the study of their condition of formation. Improved chemical and mineralogical characterization achieved with this new approach will be used in the future to improve our understanding of chondrite matrix origin and evolution. We made available an open source code allowing to execute all the different steps to offer the possibility to apply ACADEMY to study any submicrometric mineral assemblages (silt porosity measurements, analyses of growth or reaction rims, shock effects on minerals, and the nature of breccias).

\section{Acknowledgments}

We thank the two anonymous reviewers, especially the first one, for its constructive comments which helped to improve the manuscript as well as professor Balz Kamber (AE) for handling the manuscript. We thank the Department of Mineral Sciences of the Smithsonian institution for providing us with microbeam reference standards (catalog number: 117733-85276-111356-115900-114887-R2460). We thank the SARM (Service d'Analyse des Roches et des Minéraux) for providing us the Biotite. We thank the Muséum National d'Histoire Naturelle (Paris) for providing the sections of meteorites. We thank Ahmed Addad and Séverine Bellayer for their assistance with the electron microscope instruments. This work was supported by the Programme National de Planétologie (PNP) of CNRS/INSU, co-funded by CNES. The SEM and EPMA work was done at the electron microscope facility at the University of Lille with the support of the Chevreul Institute, the European FEDER and Région Hauts-de-France. Finally, P-M. Z thanks the Hyperspy developer team more specifically Francisco de la Pena and Thomas Aarholt for their debugging help and for their assistance in merging the background modeling into Hyperspy. 


\section{REFERENCES}

Anders, E., \& Grevesse, N. (1989, 1). Abundances of the elements: Meteoritic and solar. Geochimica et Cosmochimica acta, 53, 197-214. doi:10.1016/0016-7037(89)90286-х

Anovitz, L. M., \& Cole, D. R. (2015). Characterization and Analysis of Porosity and Pore Structures. Reviews in Mineralogy and Geochemistry, 80, 61-164. doi:https://doi.org/10.2138/rmg.2015.80.04

Barber, D. J. (1981, 6). Matrix phyllosilicates and associated minerals in C2M carbonaceous chondrites. Geochimica et Cosmochimica Acta, 45, 945-970. doi:10.1016/0016-7037(81)90120-4

Barrat, J.-A., Zanda, B., Moynier, F., Bollinger, C., Liorzou, C., \& Bayon, G. (2012, 4). Geochemistry of $\mathrm{CI}$ chondrites: Major and trace elements, and $\mathrm{Cu}$ and $\mathrm{Zn}$ isotopes. Geochimica et Cosmochimica Acta, 83, 79-92. doi:10.1016/j.gca.2011.12.011

Bass, M. N. (1971, 2). Montmorillonite and serpentine in Orgueil meteorite. Geochimica et Cosmochimica Acta, 35, 139-147. doi:10.1016/0016-7037(71)90053-6

Bernatowicz, T. J., Cowsik, R., Gibbons, P. C., Lodders, K., Fegley, B., Amari, S., \& Lewis, R. S. (1996). Constraints on stellar grain formation from presolar graphite in the Murchison meteorite. The Astrophysical Journal, 472, 760. doi:10.1086/178105

Berrier, J., Hallaire, V., \& Curmi, P. (1999). Assemblage des constituants fins et grossiers du sol a l'echelle microscopique. Quantification par analyse d'image. COLLOQUES-INRA, 17-28.

Bostrom, K., \& Fredriksson, K. (1965). Surface conditions of the Orgueil meteorite parent body as indicated by mineral associations.

Brearley, A. J. (1993, 4). Matrix and fine-grained rims in the unequilibrated CO3 chondrite, ALHA77307: Origins and evidence for diverse, primitive nebular dust components. Geochimica et Cosmochimica Acta, 57, 1521-1550. doi:10.1016/0016-7037(93)90011-k

Brearley, A. J. (2006). The action of water. Meteorites and the early solar system II, 587-624.

Brisset, F., Repoux, M., Grillon, J. R., \& Robaut, F. (2008). Microscopie électronique à balayage et microanalyses. Les Ulis: EDP Sciences.

Chantler, C. T., Olsen, K. J., Dragoset, R. A., Kishore, A. R., Kotochigova, S. A., \& Zucker, D. S. (2003). $\mathrm{X}$-Ray form factor, attenuation and scattering tables (version 2.0). http://physics. nist. gov/ffast. Retrieved from https://physics.nist.gov/PhysRefData/FFast/Text2000/contents2000.html

Chen, L., Xu, J., \& Chen, J. (2015, 10). Applications of scanning electron microscopy in earth sciences. Science China Earth Sciences, 58, 1768-1778. doi:10.1007/s11430-015-5172-9

Chizmadia, L. J., \& Brearley, A. J. (2008, 1). Mineralogy, aqueous alteration, and primitive textural characteristics of fine-grained rims in the Y-791198 CM2 carbonaceous chondrite: TEM observations and comparison to ALHA81002. Geochimica et Cosmochimica Acta, 72, 602-625. doi:https://doi.org/10.1016/j.gca.2007.10.019

Clayton, R. N., \& Mayeda, T. K. $(1984,2)$. The oxygen isotope record in Murchison and other carbonaceous chondrites. Earth and Planetary Science Letters, 67, 151-161. doi:https://doi.org/10.1016/0012-821X(84)90110-9 
Cuzzi, J. N., \& Olson, D. M. (2017, 3). Recovering 3D particle size distributions from 2D sections. Meteoritics \& Planetary Science, 52, 532-545. doi:10.1111/maps.12812

De la peña, F., Ostasevicius, T., Fauske, V. T., Burdet, P., Jokubauskas, P., Nord, M., . . Chang, H.-W. (2017, 5). hyperspy/hyperspy: HyperSpy 1.3. doi:10.5281/zenodo.583693

Drouin, D., Couture, A. R., Joly, D., Tastet, X., Aimez, V., \& Gauvin, R. (2007). CASINO V2. 42-A Fast and Easy-to-use Modeling Tool for Scanning Electron Microscopy and Microanalysis Users. Scanning, 29, 92-101. doi:10.1002/sca.20000

Fuchs, L. H., Olsen, E., \& Jensen, K. J. (1973). Mineralogy, mineral-chemistry, and composition of the Murchison (C2) meteorite. Smithsonian Contributions to the Earth Sciences, 1-39. doi:10.5479/si.00810274.10.1

Goldstein, J. I., Newbury, D. E., Michael, J. R., Ritchie, N. W., Scott, J. H., \& Joy, D. C. (2017). Scanning electron microscopy and $X$-ray microanalysis. Springer.

Govindaraju, K., \& Roelandts, I. (1988). Compilation Report (1966-1987) on Trace Elements in five CRPG Geochemical Reference Samples: Basalt BR; Granites, GA and GH; Micas, Biotite MicaFe and Phlogopite Mica-Mg. Geostandards Newsletter, 12, 119-201.

Greshake, A. $(1997,1)$. The primitive matrix components of the unique carbonaceous chondrite Acfer 094: A TEM study. Geochimica et Cosmochimica Acta, 61, 437-452. doi:https://doi.org/10.1016/S0016-7037(96)00332-8

Heinrich, K. F. (1986). Mass absorption coefficients for electron probe microanalysis. Proc. 11th Int. Congr. on X-Ray Optics and Microanalysis, 67-119.

Hellmuth, K. H., Siitari-Kauppi, M., \& Lindberg, A. (1993, 6). Study of porosity and migration pathways in crystalline rock by impregnation with 14C-polymethylmethacrylate. Journal of Contaminant Hydrology, 13, 403-418. doi:https://doi.org/10.1016/0169-7722(93)90073-2

Henke, B. L., Gullikson, E. M., \& Davis, J. C. (1993). X-ray interactions: photoabsorption, scattering, transmission and reflection $\mathrm{E}=50-30,000 \mathrm{eV}, \mathrm{Z}=1-92$.

Hewins, R. H. (1997, 5). CHONDRULES. Annual Review of Earth and Planetary Sciences, 25, 61-83. doi:https://doi.org/10.1146/annurev.earth.25.1.61

Ichinokawa, T., Kobayashi, H., \& Nakajima, M. $(1969,12)$. Density effect of X-ray emission from porous specimens in quantitative electron probe microanalysis. Japanese journal of applied physics, 8 , 1563. doi:10.1143/jjap.8.1563

Jarosewich, E. (1990, 12). Chemical analyses of meteorites: A compilation of stony and iron meteorite analyses. Meteoritics, 25, 323-337. doi:10.1111/j.1945-5100.1990.tb00717.x

Jarosewich, E. (2006, 9). Chemical analyses of meteorites at the Smithsonian Institution: An update. Meteoritics \& Planetary Science, 41, 1381-1382. doi:10.1111/j.1945-5100.2006.tb00528.x

Kerridge, J. F., \& Macdougall, J. D. (1976, 3). Mafic silicates in the Orgueil carbonaceous meteorite. Earth and Planetary Science Letters, 29, 341-348. doi:10.1016/0012-821x(76)90138-2

Kramers, H. A. (1923). XCIII. On the theory of X-ray absorption and of the continuous X-ray spectrum. The London, Edinburgh, and Dublin Philosophical Magazine and Journal of Science, 46, 836871. doi:10.1080/14786442308565244 
Krot, A. N., Amelin, Y., Bland, P., Ciesla, F. J., Connelly, J., Davis, A. M., . . Yin, Q.-Z. (2009, 9). Origin and chronology of chondritic components: A review. Geochimica et Cosmochimica Acta, 73, 4963-4997. doi:https://doi.org/10.1016/j.gca.2008.09.039

Kvenvolden, K., Lawless, J., Pering, K., Peterson, E., Flores, J., Ponnamperuma, C., . . Moore, C. (1970, 12). Evidence for extraterrestrial amino-acids and hydrocarbons in the Murchison meteorite. Nature, 228, 923. doi:10.1038/228923a0

Lanari, P., Vidal, O., De Andrade, V., Dubacq, B., Lewin, E., Grosch, E. G., \& Schwartz, S. (2014). XMapTools: A MATLAB $\odot$-based program for electron microprobe X-ray image processing and geothermobarometry. Computers \& Geosciences, 62, 227-240. doi:10.1016/j.cageo.2013.08.010

Landry, M. R. (2005, 8). Thermoporometry by differential scanning calorimetry: experimental considerations and applications. Thermochimica Acta, 433, 27-50. doi:https://doi.org/10.1016/j.tca.2005.02.015

Lauretta, D. S., Hua, X., \& Buseck, P. R. (2000, 10). Mineralogy of fine-grained rims in the alh $81002 \mathrm{~cm}$ chondrite. Geochimica et Cosmochimica Acta, 64, 3263-3273. doi:https://doi.org/10.1016/S00167037(00)00425-7

Le Guillou, C. L., Bernard, S., Brearley, A. J., \& Remusat, L. (2014, 4). Evolution of organic matter in Orgueil, Murchison and Renazzo during parent body aqueous alteration: In situ investigations. Geochimica et Cosmochimica Acta, 131, 368-392. doi:https://doi.org/10.1016/j.gca.2013.11.020

Le Guillou, C., \& Brearley, A. (2014, 4). Relationships between organics, water and early stages of aqueous alteration in the pristine CR3.0 chondrite MET 00426. Geochimica et Cosmochimica Acta, 131, 344-367. doi:https://doi.org/10.1016/j.gca.2013.10.024

Le Guillou, C., Changela, H. G., \& Brearley, A. J. (2015). Widespread oxidized and hydrated amorphous silicates in CR chondrites matrices: Implications for alteration conditions and H2 degassing of asteroids. Earth and Planetary Science Letters, 420, 162-173. doi:https://doi.org/10.1016/j.eps1.2015.02.031

Leapman, R. D., \& Swyt, C. R. (1988, 1). Separation of overlapping core edges in electron energy loss spectra by multiple-least-squares fitting. Ultramicroscopy, 26, 393-403. doi:https://doi.org/10.1016/0304-3991(88)90239-2

Lepy, M., Mantler, M., \& Beckhoff, B. (2008). International initiative on X-ray fundamental parameters. Retrieved from http://www.nucleide.org/IIFP.htm

Leroux, H., Cuvillier, P., Zanda, B., \& Hewins, R. H. (2015, 12). GEMS-like material in the matrix of the Paris meteorite and the early stages of alteration of CM chondrites. Geochimica et Cosmochimica Acta, 170, 247-265. doi:10.1016/j.gca.2015.09.019

Lifshin, E., \& Gauvin, R. (2001). Minimizing errors in electron microprobe analysis. Microscopy and Microanalysis, 7, 168-177.

Liu, Y., King, H., Huis, M., Drury, M., \& Plümper, O. (2016, 10). Nano-Tomography of Porous Geological Materials Using Focused Ion Beam-Scanning Electron Microscopy. Minerals, 6, 104. doi:https://doi.org/10.3390/min6040104

Lodders, K., \& Palme, H. (2009). Solar system elemental abundances in 2009. Meteoritics and Planetary Science Supplement, 72, 5154. 
Lodders, K., Palme, H., \& Gail, H.-P. (2009). 4.4 Abundances of the elements in the Solar System. In Solar system (pp. 712-770). Springer. doi:10.1007/978-3-540-88055-4_34

Mackinnon, I. D. (1980). Structures and textures of the Murchison and Mighei carbonaceous chondrite matrices. Lunar and Planetary Science Conference Proceedings, 11, pp. 839-852.

Mackinnon, I. D., \& Zolensky, M. E. (1984). Proposed structures for poorly characterized phases in C2M carbonaceous chondrite meteorites. Nature, 309, 240-242.

Marrocchi, Y., Gounelle, M., Blanchard, I., Caste, F., \& Kearsley, A. T. (2014). The Paris CM chondrite: Secondary minerals and asteroidal processing. Meteoritics \& Planetary Science, 49, 1232-1249. doi:10.1111/maps.12329

McSween Jr, H. Y., \& Richardson, S. M. (1977, 8). The composition of carbonaceous chondrite matrix. Geochimica et Cosmochimica Acta, 41, 1145-1161. doi:10.1016/0016-7037(77)90110-7

Nagy, B., \& Andersen, C. A. (1964). Electron probe microanalysis of some carbonate, sulfate and phosphate minerals in the Orgueil meteorite. American Mineralogist: Journal of Earth and Planetary Materials, 49, 1730-1736.

Nagy, B., Meinschein, W. G., \& Hennessy, D. J. (1963, 12). Aqueous, low temperature environment of the Orgueil meteorite parent body. Annals of the New York Academy of Sciences, 108, 534-552. doi:10.1111/j.1749-6632.1963.tb13407.x

Nazarov, M. A., Ignatenko, K. I., \& Shevaleevsky, I. D. (1982). Source of errors in defocussed beam analysis with the electron probe, revisited. Lunar and Planetary Science Conference, 13, pp. 582583.

Oila, E., Sardini, P., Siitari-Kauppi, M., \& Hellmuth, K.-H. (2005). The 14C-polymethylmethacrylate (PMMA) impregnation method and image analysis as a tool for porosity characterization of rockforming minerals. Geological Society, London, Special Publications, 240, 335-342.

Palme, H., \& Beer, H. (1993). The composition of chondritic meteorites. In Instruments; Methods; Solar System (Vol. 3, pp. 198-221). Landolt-Börnstein Group VI, Astronomy and Astrophysics Springer-Verlag.

Piani, L., Yurimoto, H., \& Remusat, L. (2017). A dual origin for water in the CM carbonaceous chondrites. Lunar and Planetary Science Conference, 48.

Pignatelli, I., Marrocchi, Y., Mugnaioli, E., Bourdelle, F., \& Gounelle, M. (2017, 7). Mineralogical, crystallographic and redox features of the earliest stages of fluid alteration in CM chondrites. Geochimica et Cosmochimica Acta, 209, 106-122. doi:https://doi.org/10.1016/j.gca.2017.04.017

Pret, D., Sammartino, S., Beaufort, D., Meunier, A., Fialin, M., \& Michot, L. J. (2010, 9). A new method for quantitative petrography based on image processing of chemical element maps: Part I. Mineral mapping applied to compacted bentonites. American Mineralogist, 95, 1379-1388. doi:https://doi.org/10.2138/am.2010.3431

Reid, A. M., Bass, M. N., Fujita, H., Kerridge, J. F., \& Fredriksson, K. (1970, 11). Olivine and pyroxene in the Orgueil meteorite. Geochimica et Cosmochimica Acta, 34, 1253-1255. doi:10.1016/00167037(70)90063-3

Ritchie, N. W. (2009). Spectrum Simulation in DTSA-II. Microscopy and Microanalysis, 15, 454-468. doi:10.1017/S1431927609990407 
Russell, S. S., Connolly Jr, H. C., \& Krot, A. N. (2018). Chondrules: Records of Protoplanetary Disk Processes (Vol. 22). Cambridge University Press.

Saporta, G. (2006). Probabilités, analyse des données et statistique. Editions Technip.

Schlossmacher, P., Klenov, D. O., Freitag, B., Harrach, S., \& Steinbach, A. (2010). Nanoscale chemical compositional analysis with an innovative S/TEM-EDX system. Microscopy and analysis, S5.

Scott, E. R., \& Krot, A. N. (2003). Chondrites and their components. Treatise on geochemistry, 1, 711.

Sewell, D. A., Love, G., \& Scott, V. D. (1985). Universal correction procedure for electron-probe microanalysis. II. The absorption correction. Journal of Physics D: Applied Physics, 18, 1245. doi:10.1088/0022-3727/18/7/011

Small, J. A., Leigh, S. D., Newbury, D. E., \& Myklebust, R. L. (1987, 1). Modeling of the bremsstrahlung radiation produced in pure-element targets by 10-40 keV electrons. Journal of Applied Physics, 61, 459-469. doi:10.1063/1.338245

Statham, P. J. (1976, 7). The generation, absorption and anisotropy of thick-target bremsstrahlung and implications for quantitative energy dispersive analysis. X-Ray Spectrometry, 5, 154-168. doi:10.1002/xrs. 1300050310

Statham, P., Penman, C., \& Duncumb, P. (2016, 2). Improved spectrum simulation for validating sem-eds analysis. IOP Conference Series: Materials Science and Engineering, 109. doi:10.1088/1757$899 \mathrm{x} / 109 / 1 / 012016$

Tomeoka, K., \& Buseck, P. R. (1985, 10). Indicators of aqueous alteration in CM carbonaceous chondrites: Microtextures of a layered mineral containing Fe, S, O and Ni. Geochimica et Cosmochimica Acta, 49, 2149-2163. doi:https://doi.org/10.1016/0016-7037(85)90073-0

Tomeoka, K., \& Buseck, P. R. (1988, 6). Matrix mineralogy of the Orgueil CI carbonaceous chondrite. Geochimica et Cosmochimica Acta, 52, 1627-1640. doi:https://doi.org/10.1016/00167037(88)90231-1

Tovey, N. K., \& Krinsley, D. H. (1991, 12). Mineralogical mapping of scanning electron micrographs. Sedimentary Geology, 75, 109-123. doi:https://doi.org/10.1016/0037-0738(91)90053-G

Trigo, J. M., Vila-Ruaix, A., Alonso-Azcárate, J., \& Abad, M. M. (2017). Murchison CM2 chondrite at nanoscale: evidence for hydrated minerals in the protoplanetary disk. Highlights on Spanish Astrophysics IX, Proceedings of the XII Scientific Meeting of the Spanish Astronomical Society held on July 18-22, 2016, in Bilbao, Spain, ISBN 978-84-606-8760-3. S. Arribas, A. AlonsoHerrero, F. Figueras, C. Hernández-Monteagudo, A. Sánchez-Lavega, S. Pérez-Hoyos (eds.), 2017, p. 531-542, (pp. 531-542).

Vacher, L. G., Marrocchi, Y., Verdier-Paoletti, M. J., Villeneuve, J., \& Gounelle, M. (2016, 8). Inward radial mixing of interstellar water ices in the solar protoplanetary disk. The Astrophysical journal letters, 827, L1. doi:10.3847/2041-8205/827/1/1

Vinogradoff, V., Guillou, C. L., Bernard, S., Binet, L., Cartigny, P., Brearley, A. J., \& Remusat, L. (2017, 9). Paris vs. Murchison: Impact of hydrothermal alteration on organic matter in CM chondrites. Geochimica et Cosmochimica Acta, 212, 234-252. doi:https://doi.org/10.1016/j.gca.2017.06.009

Warren, P. H. (1997). The unequal host-phase density effect in electron probe defocused beam analysis: an easily correctable problem. Lunar and Planetary Science Conference, 28, p. 1497. 
Wasson, J. T., \& Kallemeyn, G. W. (1988, 7). Compositions of chondrites. Phil. Trans. R. Soc. Lond. A, 325, 535-544. doi:10.1098/rsta.1988.0066

Wolf, D., \& Palme, H. (2001, 4). The solar system abundances of phosphorus and titanium and the nebular volatility of phosphorus. Meteoritics \& Planetary Science, 36, 559-571. doi:10.1111/j.1945-5100.2001.tb01897.x

Zanda, B., Humayun, M., Barrat, J.-A., Bourot-Denise, M., \& Hewins, R. (2011). Bulk and Matrix Composition of the Paris CM. Inferences on Parent-Body Alteration and the Origin of MatrixChondrule Complementarity. Lunar and Planetary Science Conference, 42, p. 2040.

Zanda, B., Lewin, E., \& Humayun, M. (2018). The chondritic assemblage. In Chondrules: Records of Protoplanetary Disk Processes (Vol. 22, pp. 122-150). Cambridge University Press.

Zolensky, M. E., Mittlefehldt, D. W., Lipschutz, M. E., Wang, M.-S., Clayton, R. N., Mayeda, T. K., .. . David, B. (1997, 12). CM chondrites exhibit the complete petrologic range from type 2 to 1. Geochimica et Cosmochimica Acta, 61, 5099-5115. doi:https://doi.org/10.1016/S00167037(97)00357-8

Zolensky, M., Barrett, R., \& Browning, L. (1993, 7). Mineralogy and composition of matrix and chondrule rims in carbonaceous chondrites. Geochimica et Cosmochimica Acta, 57, 3123-3148. doi:10.1016/0016-7037(93)90298-b 


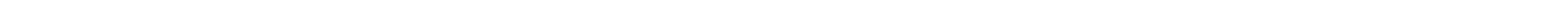



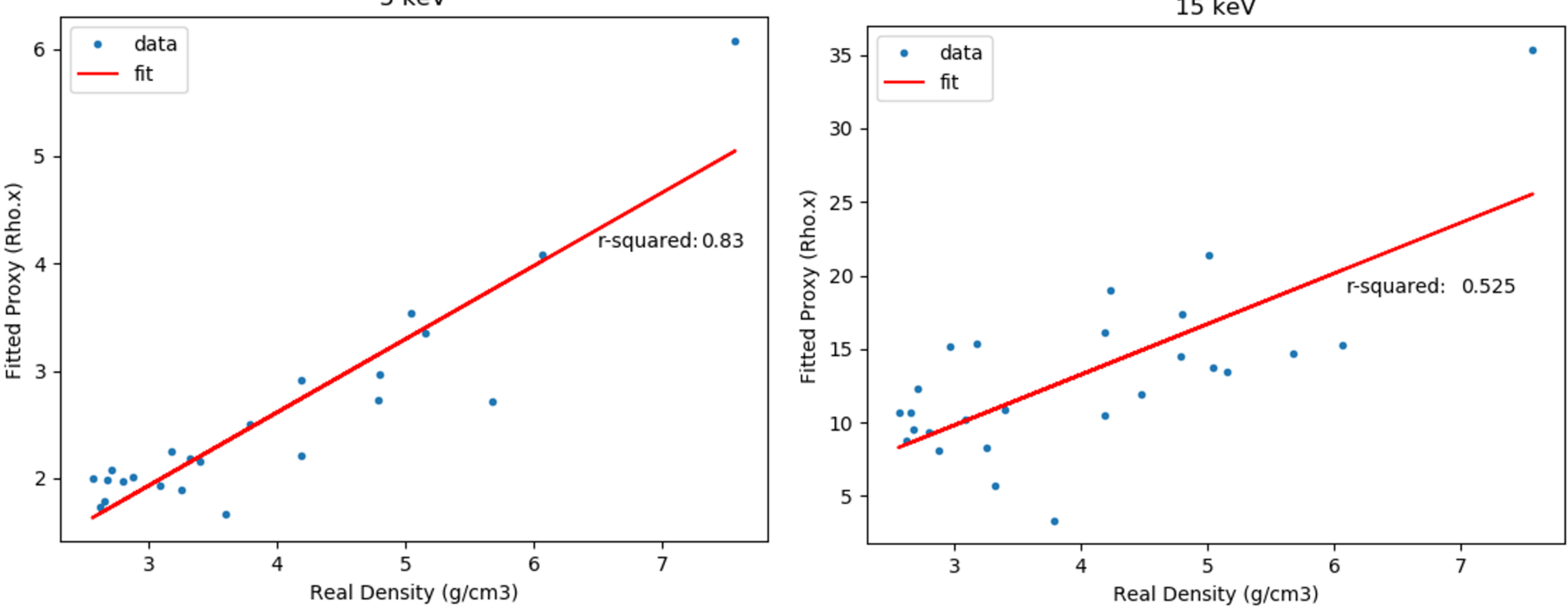
A

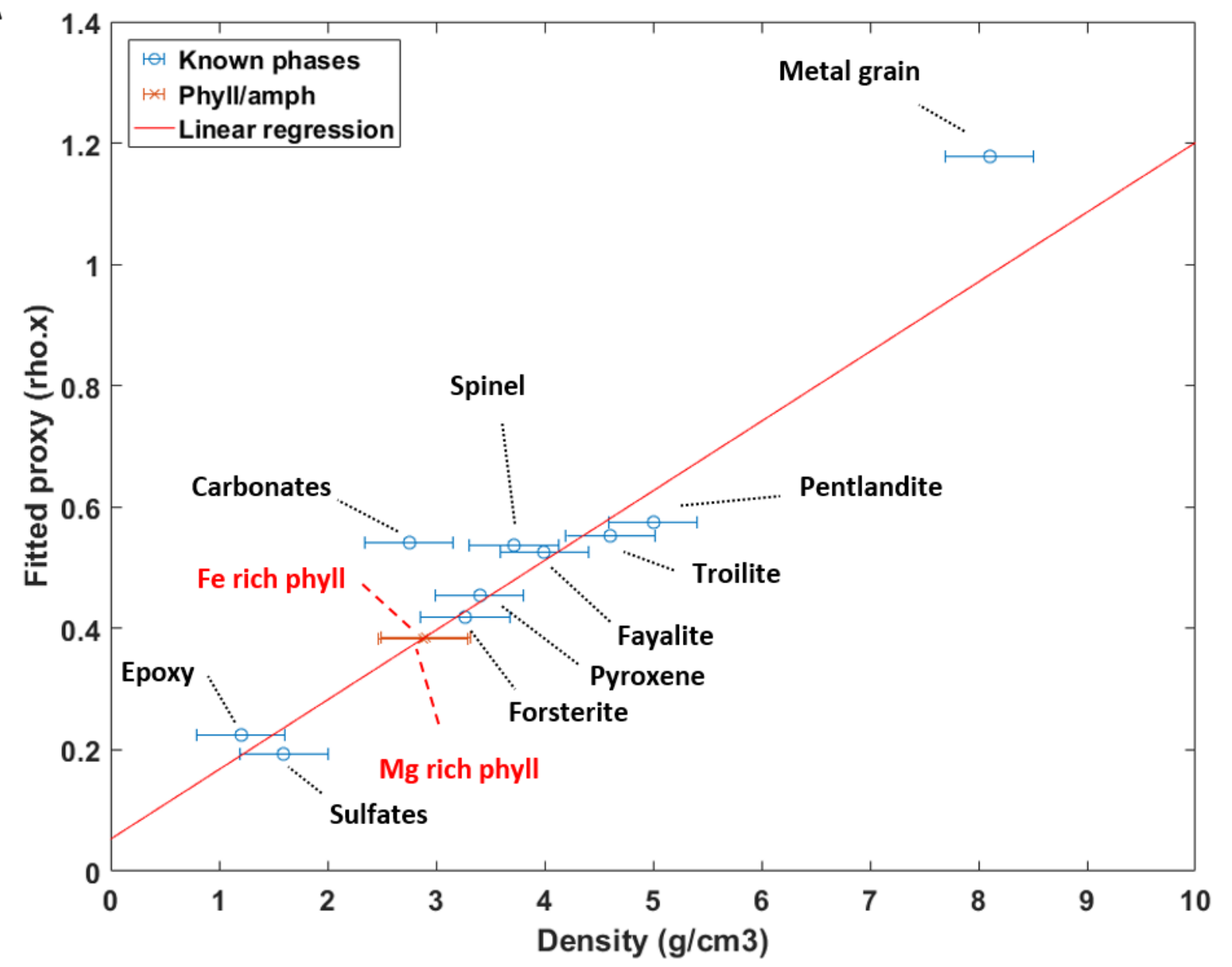

B

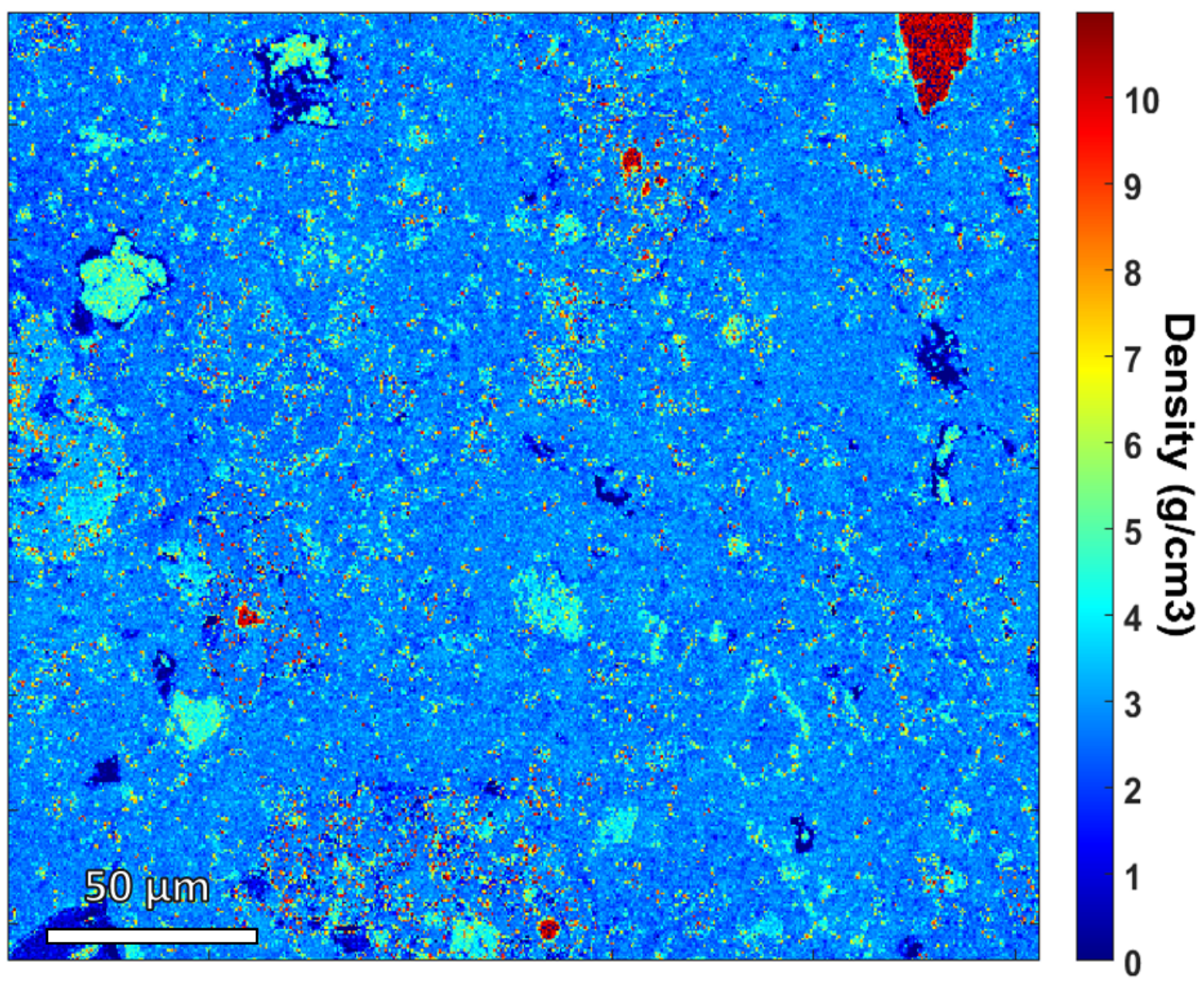




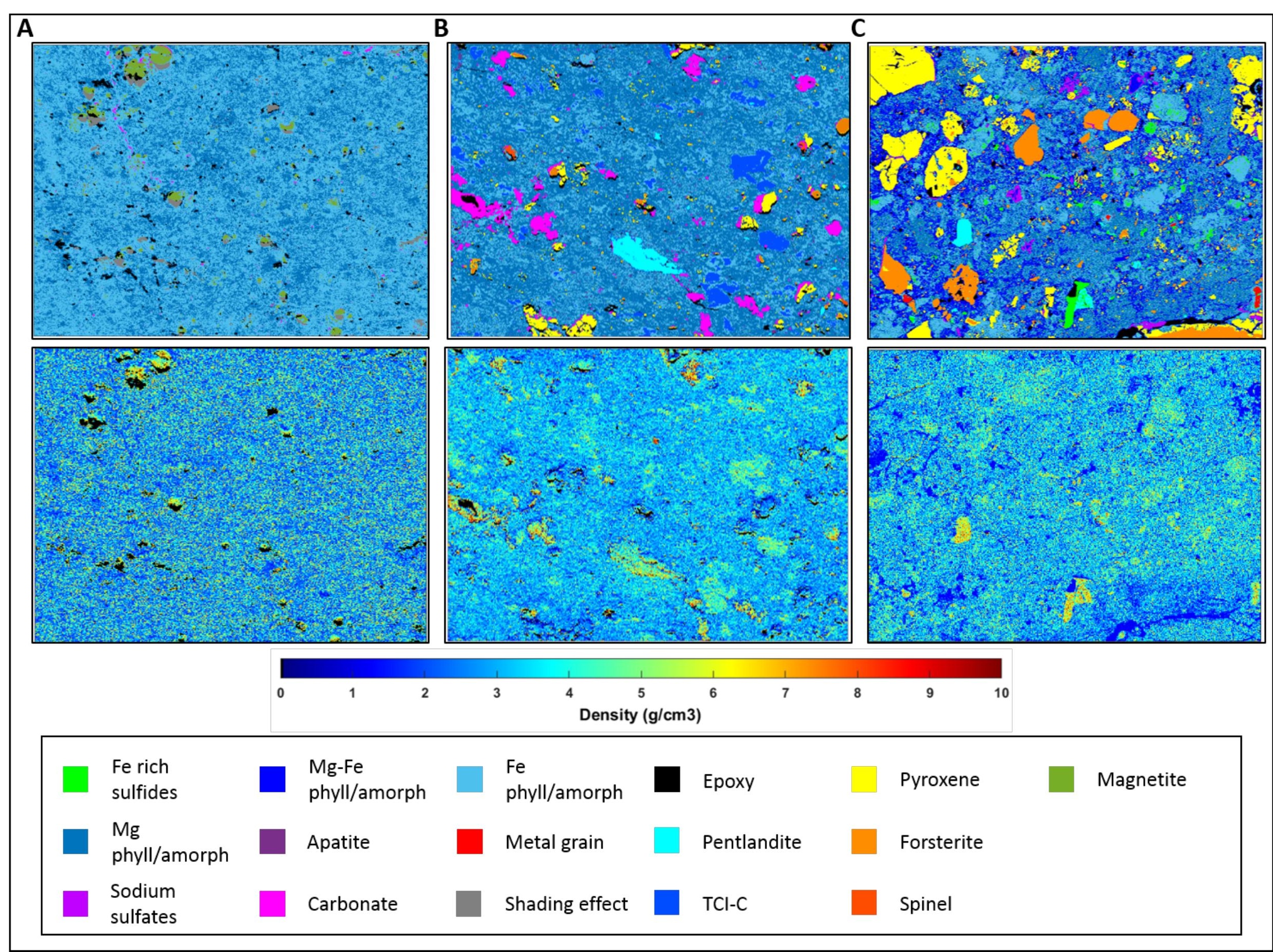



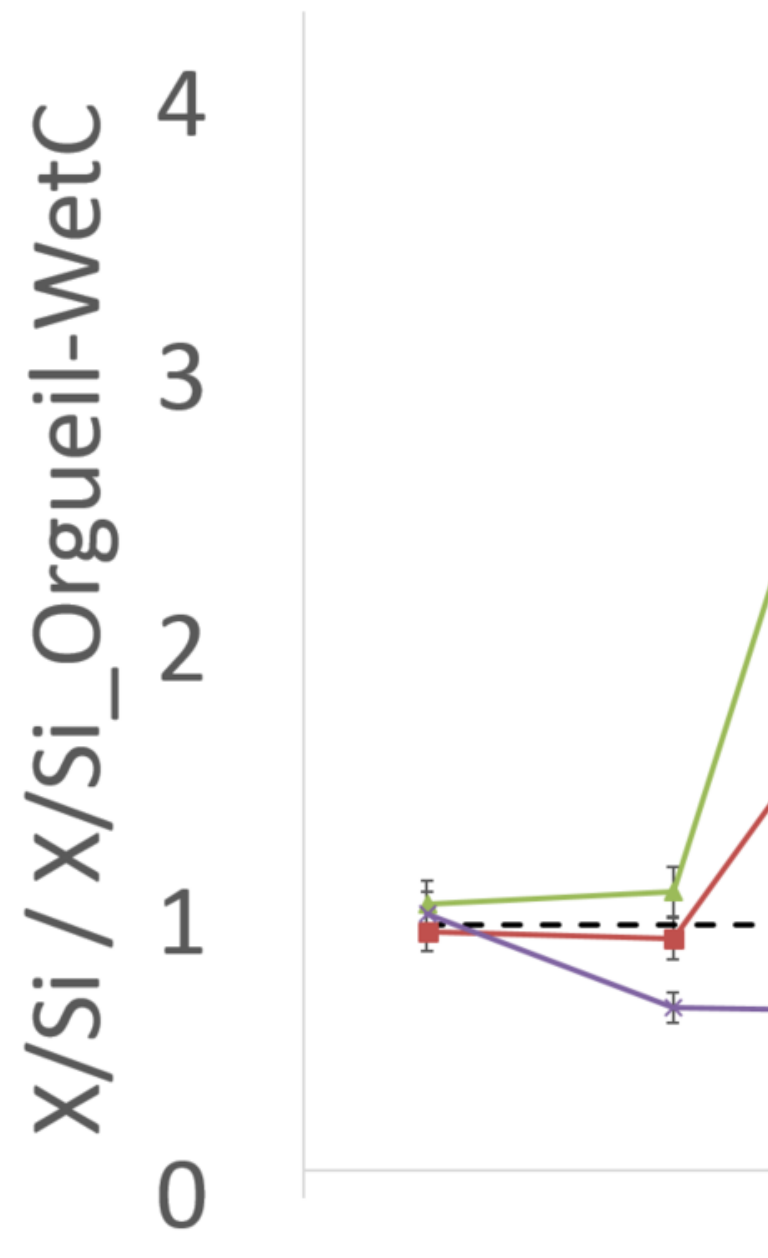

- - Orgueil wet chemistry --Paris

$\rightarrow$ Murchison

*Orgueil

0
Al
$\mathrm{Ti}$
$\mathrm{Ca}$
$\mathrm{Ni}$
$\mathrm{Mg} \quad \mathrm{Fe}$
Si $\mathrm{Cr}$
P
S
K
$\mathrm{Na}$ 

(1) Standard closer in composition (2) Including $\mathrm{H}_{2} \mathrm{O}$ in ZAF calculation (3) Wheighing modal abundances by specific densities

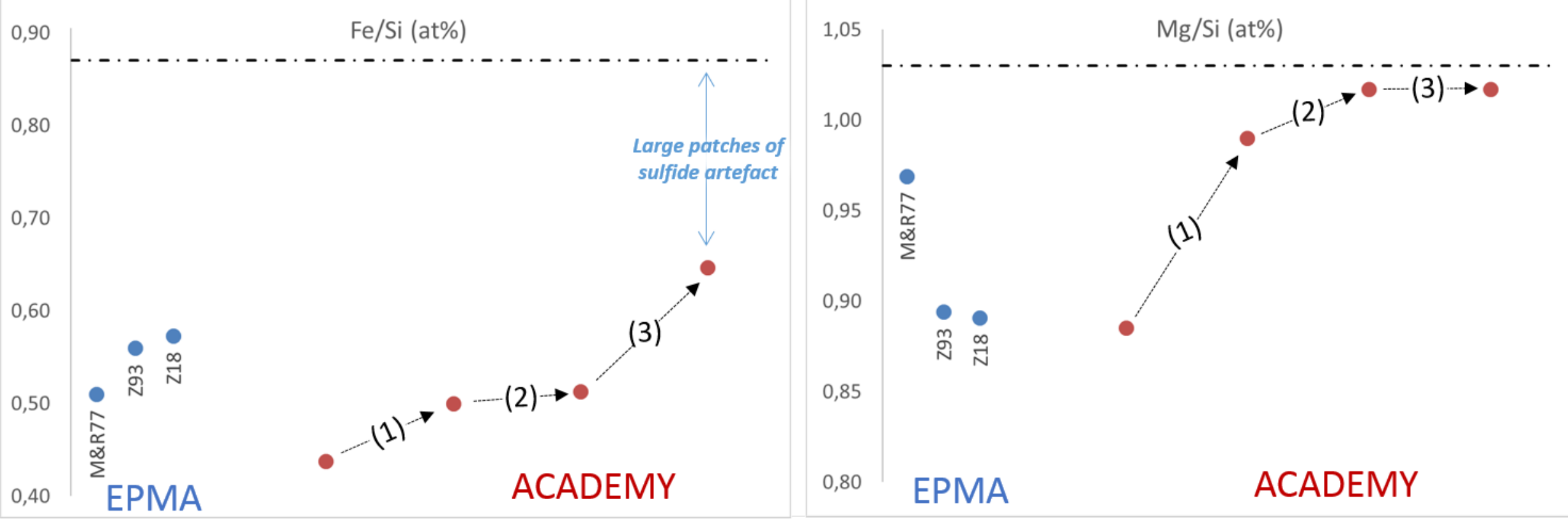



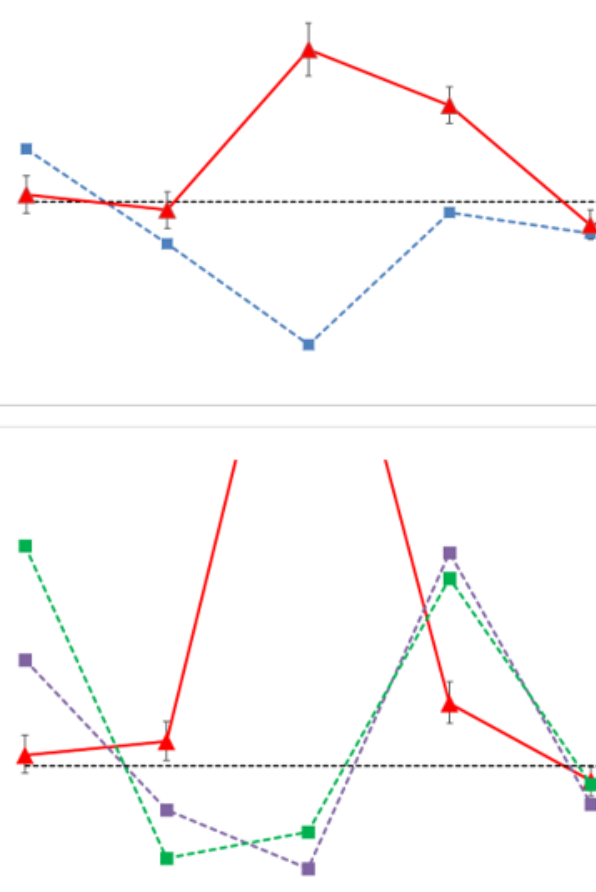

Murchison

- McSween and Richardson 1977

Zanda et al. 2011

- Zolensky et al. 1993

$\begin{array}{lllllllllllll}\mathrm{Al} & \mathrm{Ti} & \mathrm{Ca} & \mathrm{Ni} & \mathrm{Mg} & \mathrm{Fe} & \mathrm{Si} & \mathrm{Cr} & \mathrm{P} & \mathrm{S} & \mathrm{K}\end{array}$




\begin{tabular}{|c|c|c|}
\hline Phase & Abundances in \% & Relative error (1) in \% \\
\hline Forsteritic Olivine & 4.46 & 0.64 \\
Pyroxene & 21.05 & 2.88 \\
Pentlandite & 1.77 & 1.19 \\
Pyrrhotite & 5.28 & 0.84 \\
Metal grain & 3.12 & 1.82 \\
Mg-rich phyll/amorph & 47.24 & 12.99 \\
Fe-rich phyll/amorph & 5.89 & 8.19 \\
Spinel & 1.20 & 1.75 \\
Sulfates & 5.37 & 2.84 \\
Carbonates & 4.61 & 3.10 \\
Ferroan olivine & 4.82 & 0.71 \\
\hline
\end{tabular}




\begin{tabular}{|c|c|c|}
\hline & Paris Zone 2 & Absolute error \\
\hline$N a$ & 0.78 & 0.05 \\
$M g$ & 23.32 & 0.87 \\
$S i$ & 27.14 & 0.97 \\
$F e$ & 28.49 & 1 \\
$A l$ & 2.63 & 0.11 \\
$K$ & 0.13 & 0.01 \\
$S$ & 10.01 & 0.4 \\
$C a$ & 4.56 & 0.18 \\
$P$ & 0.29 & 0.02 \\
$T i$ & 0.07 & 0 \\
$C r$ & 0.41 & 0.02 \\
$N i$ & 2.16 & 0.09 \\
\hline$T o t a l$ & 100 & \\
\hline
\end{tabular}

